DETERMINANTS OF EARTH CIRCLE SITE LOCATION IN THE MORETON REGION, SOUTHEAST QUEENSLAND

\section{LEONN SATTERTHWAIT}

Anthropology \& Sociology

oniversity of Queensland and

\author{
ANDREW HEATHER
}

Social \& Cultural studies School of Education James Cook University of North gueengland

\title{
INTRODUCTION
}

Several studies, both anthropological and archaeological, have drawn attention to the broader social, economic, and political implications of Aboriginal ceremonial activities, as well as highlighted the role of ceremonial involvment as a mechanism of change in Aboriginal Australia (e.g., Altman 1983, 1987; Barker 1976; Bern 1979; Hamilton 1980; Lourandos 1980; 1983, 1985; Myers 1980a, 1980b; Satterthwait 1987; Thomson 1949). The difficulty, from an archaeological perspective, is to locate demonstrable evidence of these activities.

Earth circle sites ("Bora rings") provide such evidence. These sites are conspicuous features of the southeast Queensland archaeological landscape not only because of their prevalence in the area, but also because they constitute sites whose functions were expressly social and ceremonial. Consequently, earth circles are of particular significance as material expressions of a fundamental dimension of Aboriginal life, and for this reason, their considered examination is critical to a more complete understanding of the archaeology of the region.

Earth circles figured in a number of complex social, cultural and environmental relationships, and there are several intriguing lines of inquiry that could be pursued with regard to them. The principal aim of this paper, however, is to identify the factors determining their distribution and location in the region. As will be demonstrated, environmental factors appear to have been of particular importance, especially those associated with the provision of resources for the often large numbers of people gathered at earth circle sites. In giving attention to variables of this kind, we are not arguing that the gathering of people for ceremonial and other activities was necessarily prompted by economic need, but that no matter what the motivation for earth circle construction and use, suitable environmental conditions were a necessary prerequisite (cf. Hall 1982:85; Sullivan 1977:60;. Riches 1982:51-52). As a result, these factors had a major bearing on earth circle locational attributes. 
The terms "earth circle" and "earth circle site" are used in the following in preference to the common generic term "Bora ring". The term "Bora ring" has specific reference to the ceremonial grounds used by the Aboriginal people of north-central New south wales for initiations or "Boras" (Mathews 1894:98-99); different terms were used by the Aboriginal peoples of Southeast Queensland. Moreover, the uses of earth circles were not confined to initiation, but also included dances and fights. Given these considerations, application of the term "Bora ring" to all earth circle sites is best avoided.

For the purposes of this study, investigation was limited to the Moreton Region of Southeast queensland as defined by the Co-ordinator General's Department (1972). Confining the study to this region has a number of advantages. The region represents the northern part of the zone in which it appears earth circles were constructed in greatest number. In addition, the availability of a considerable body of archaeological, environmental and historical information for the region greatly facilitates any study of earth circles. Finally, although the region is delimited by the borders of a governmental statistical division, it comes close to representing a natural geographic region, this because it is bounded by Moreton Bay and the Pacific Ocean on the east, the McPherson and Great Dividing Ranges on the south and west, and the Brisbane and various coastal ranges on the north.

\section{RESEARCH METHODS}

In order to pursue the aims of the project it was necessary to draw on historical, archaeological and environmental data: Historical accounts provide the only available primary evidence regarding the specific uses of sites, the provenance and attributes of, sites no longer extant, and Aboriginal criteria for site location; archaeological examination of existing sites allowed determination of the details of site location and morphology; and the collection of environmental data enabled consideration of the relationship between, site location and various environmental factors.

Data of all three kinds were obtained and analyzed at several levels of detail and, fol lowing McBryde (1979:144,146), data in one category were tested against data in the other categories.

The population targeted for investigation was taken to be all the earth circle sites of known location in the Moreton region. Since important aspects of the analysis did not require physical inspection of sites, but rather knowledge of site locality and surroundings, the study population includes both existing sites and sites that have been destroyed.

A master site list was compiled from the records of the Archaeology Branch, Queensland Department of Community services, gupplemented by information derived from the Bornong Project list (Marks 1970), University of Queensland Archives (Robinson 1952), Queensland Museum correspondence files, various local informants, and the work of J.G. steele (1984). From these sources, a list of 108 sites was drawn up (Heather 1983:Appendix 1). of these, however, there are reliable details of location for only 62 . The remainder are of equivocal or generalized location, or are apparent duplications. Although the master list of 108 reported sites is the result of extensive research, it is not exhaustive. Several sites previously 
unrecorded were encountered in the course of fieldwork, and no doubt additional sites await discovery or recording. At any rate, for the purposes of this paper, the study population consists of the 62 sites, extant or destroyed, for which adequate locality information could be obtained. These sites are listed in Table 1 and their locations indicated in Figure 1.

Much of the analysis involved collating information from Archaeology Branch files, thematic maps, the historical literature and a variety of other sources. An attempt was also made to check sites in the field, but since available resources would not allow field assessment of all the site localities in the study population, a 338 sample was selected for detailed field examination. It was important for later analysis that this sample reflect the study population with regard to site morphology and geographical distribution. Consequently, a doubly representative sample was required, and this precluded use of random sampling procedures. The population was divided into six morphological types on the basis of number of circles and presence or absence of a pathway. A third of the sites of each type were then randomly selected. Several such stratified samples were drawn and the one with the best areal. coverage chosen, this to ensure adequate representation of the population's geographical distribution. The results derived from map and other analyses of the study population as a whole were kept separate from the fieldwork results, and the two are presented as independent sets of data in later sections of this paper in order to al low use of one as a check on the other. The sites included in the field study sample are denoted in Table 1.

Investigation of the determinants of earth circle location focused on three facets of the problem: distributional and spatial relationships among sites; site morphology; and environmental correlates of site location. All analysis was non-destructive; no excavation was undertaken.

It is possible that earth circle locations are interdependent, that the placement of any one site was influenced by the placement of other sites. For this reason, an attempt was made to detect possible spatial relationships among sites. This task was approached at two levels, one in terms of broad distribution trends and the other in terms of relationships among individual sites. Site locations were plotted; distances between sites measured and nearest-neighbour and other analytical techniques employed to ascertain if the distribution of sites is random or is patterned in some way.

Two limitations affect the analysis of site distribution. One concerns the contemporaneity of the sites in the population. If sites are not all of equal antiquity, the present-day distribution pattern represents a palimpsest of gurviving distributions from a range of time periods (Hodder and Orton 1976:18-19,238). It seems likely, however, that the sites in the region are of broadly equal, and recent, age. Given the nature of their construction, earth circles are extremely vulnerable to destruction by natural or human agency--they exhibit, as McBryde (1974a:53) aptly puts it, a highly "evanescent character". For these reasons it is assumed, with certain possible exceptions to be discussed later, that the sites in the population are more or less contemporaneous with one another and that they date to the recent past (cf. McBryde 1974a:53). 
Table 1. The study population of known earth circle sites.

\begin{tabular}{|c|c|c|c|c|c|}
\hline No. & REFERENCE & LOCATION & & ORPHOLOGY & \\
\hline 01 & KA : A 12 & Rathdowney (S.E.) & 1 & Ring & \\
\hline 02 & A13 & Rathdowney (N.W.) & 1 & Ring within a & Ring \\
\hline $03 *$ & A16 & Palen Creek & 1 & Ring & \\
\hline 04 & $\mathrm{~KB}: \mathrm{A} 4$ & Glenore Grove & 1 & Ring + Path & \\
\hline 05 & A.5 & Somerset Dam & 2 & Rings + Path & \\
\hline 06 & A8 & Samsonvale & 2 & Rings + Path & \\
\hline 07 * & A.29 & Samford & 2 & Rings + Path & \\
\hline 08 & A 34 & Moggill & 2 & Rings + Path & \\
\hline 09 & A52 & Kippa Creek (via Northbrook) & 2 & Rings + Path & \\
\hline 10 & A53 & Mt Esk Pocket & 2 & Rings + Rath & \\
\hline 11 & A62 & Lacey's Creek & 2 & $\begin{array}{l}\text { Flat, Smooth } \\
\text { Areas }\end{array}$ & $\#$ \\
\hline 12 & A62a & Lacey'\& Creek & 1 & Ring & $\#$ \\
\hline 13 * & A72 & Camira & 2 & Rings + Path & \\
\hline 14 * & A80 & Purga Creek & 1 & Ring + Path & \\
\hline 15 & A81 & Oakey Creek & 2 & Ringa + Path & \\
\hline 16 & A97 & Wararba creek & 2 & Rings + Path & \\
\hline 17 & $A(a)$ & Buaraba & 1 & Ring + Path & $\#$ \\
\hline 18 & $A(b)$ & W. of Dayboro & 2 & Rings + Path & $\#$ \\
\hline 19 & $A(c)$ & $\begin{array}{l}\text { Junction North Pine River } \\
\text { and Pine Creek }\end{array}$ & 1 & Ring & $\#$ \\
\hline $20 *$ & $A(d)$ & $\begin{array}{l}\text { W. of Junction Briabane } \\
\text { and Stanley Rivers }\end{array}$ & 1 & Ring & \\
\hline 21 & $\mathrm{KC}: \mathrm{A} \mathbf{3}$ & Bruce Mighway-Mooloolah Road & 1 & Ring & $\#$ \\
\hline 22 & A4 & $\begin{array}{l}\text { Junction Sippy Creek } \\
\text { and Mooloolah River }\end{array}$ & 1 & Ring & \\
\hline 23 & A.7 & walli creek & 2 & Ringe + Path & \\
\hline 24 & A8 & Tung 1 & 1 & Ring & \\
\hline 25 & A10 & Moy Pocket & 1 & Ring & \\
\hline $26 *$ & A11 & $\begin{array}{l}\text { Between Beerburrum and } \\
\text { Glasshouse Mountains }\end{array}$ & $\overrightarrow{2}$ & Rings & \\
\hline 27 & A 16 & Mt Mongildale & 1 & Ring & \\
\hline 28 & $\mathrm{~A} 20$ & Bell's Creek & 2 & Rings & \\
\hline 29 & A29 & Yandina & 1 & Ring & \\
\hline 30 * & $A 40$ & Obi Obi Creek & 1 & Ring & \\
\hline $31 \star$ & A45 & Woodford & 1 & Ring & \\
\hline 32 & 248 & Donnybrook & 2 & Rings & \\
\hline 33 & A5 1 & Jimna & 2 & Bare Earth cir & reles \\
\hline 34 & A.55 & Benarkin & 2 & Rings & \\
\hline 35 & A64 & Jimna & 2 & Bare Earth Cir & rcles \\
\hline $36 *$ & A.71 & Mt Langley & 1 & Ring & $\#$ \\
\hline 37 * & LA:A7 & 6th Ave., Burleigh & 2 & Rings + Path & \\
\hline 38 & A26 & Upper Coomera River & 1 & Ring + Path & \\
\hline 39 * & A27 & Canungra & 2 & Rings + Path & $\#$ \\
\hline 40 & LB : A2 & Mt cotton & 2 & Rings & \\
\hline 41 & A3 & Nudgee & 2 & Rings + Path & \\
\hline 42 & A9 & Toorbul Point & 2 & Rings + Path & \\
\hline 43 & A10 & Hilliard'B Creek & 2 & Ring + Path & \\
\hline $44 *$ & A12-14 & Tamborine & 3 & Rings + Rath & \\
\hline 45 & A42 & Ormiston & 1 & Ring & \\
\hline 46 & A44 & W. Swan Bay, N. Stradbroke & 1 & Ring & \\
\hline 47 & A45 & S. end $N$. Stradbroke I & $\mathbf{4}$ & & \\
\hline $48 *$ & A49 & Jimboomba & $\hat{1}$ & Bare Earth Cir & $\operatorname{cole}$ \\
\hline 49 & $c 61$ & Keperra & 2 & Rings + Path & $\#$ \\
\hline 50 & c65 & Thornlands & 4 & & $\#$ \\
\hline 51 & c67 & Petrie & 2 & Rings + Path & 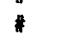 \\
\hline $52 \star$ & Bornong No. 19 & Kippa Ring & 2 & Ringe + Path & 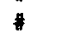 \\
\hline 53* & Bornong No. 33 & Lowood & 2 & Ringa + Path & $\#$ \\
\hline $54 *$ & Bornong No. 43 & Kipper Creek (via Esk) & 1 & Ring + Path & \\
\hline 55* & Robinson 1952 & Nerang & $\mathbf{4}$ & $\operatorname{sen}(20)$ & $\#$ \\
\hline $56 *$ & Ponosov 1964 & $\begin{array}{l}\text { Junction Albert and } \\
\text { Logan Rivers }\end{array}$ & 1 & $\begin{array}{l}\text { Earth + } 1 \text { stor } \\
\text { Circle }\end{array}$ & ne \\
\hline $57 \star$ & Ponosor & Gibson Igland & 1 & Ring & $\#$ \\
\hline 58 & Clark c. 1895 & Wooloongabba & 2 & Rings + Path & \# \\
\hline 59 & steele 1984 & Sandy Creek (via Kilcoy) & 2 & Rings & $\#$ \\
\hline $60 *$ & stockton 1979 & Coochin Creek & 1 & Ring & $\#$ \\
\hline 61 & Qld Museum & Moreton Irland & $\mathbf{2}$ & & * \\
\hline 62* & $\begin{array}{l}\text { J. Hall } \\
\text { pers. comm. }\end{array}$ & Bellara, Bribie Island & 1 & Ring & \\
\hline & uded in fie & ly sample & $\#$ & No longer ext & ant \\
\hline
\end{tabular}




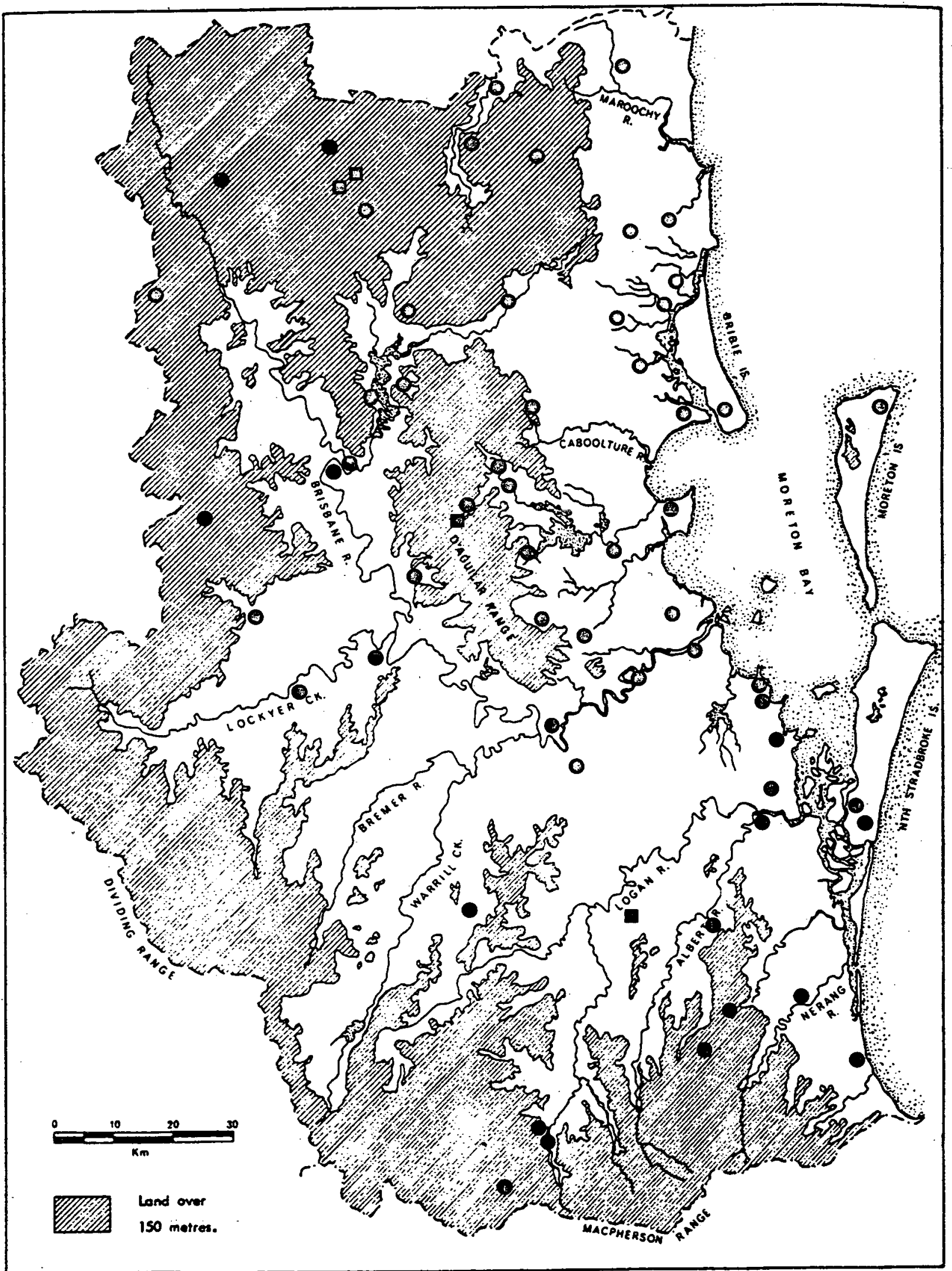

Figure 1. Location of sites in the study population (squares identify sites lacking raised perimeter mounds). 
The second limitation concerns the unknown extent and pattern of site destruction. It has been suggested that some archaeological distributions are so disturbed that spatial analysis is pointless (Hodder 1977:226). Even though it is not possible to determine how many sites initially constituted the universe of earth circles in the region, analysis was pursued on.the premise that a population of 62 sites was adequate to provide some indication of trends in their original spatial distribution. And while these sites are vulnerable to destruction, they were recognized as singular by early colonists and subsequent generations and appreciated as places of considerable significance. Hence, many sites have been preserved or their location and features noted, with the result that a large number have survived, either physically or in memory, to be documentea today.

site morphology is not only of interest in its own right, but is a potential indicator of site function, of association with particular ritual traditions or of change through time. These factors may in turn have influenced site location. If, for instance, a specific morphological type were used for a specific secular or ritual purpose, one might not expect two or more such sites to occur in close proximity. Furthermore, sites of different type may exhibit different environmental associations.

The features considered characteristic of oite morphology, and for which information could be obtained for at least part of the population, were number of circles present, circle diameter and shape, pathway direction, and overall site orientation. Such characteristics as depth of enclosed area, mound height and mound width were not included in the analysis because their determination proved to be highly problematic. Soil creep, wind and water erosion, land clearing, farming and grazing have contributed to changes in these features. As a result, measurement was limited to circle diameter from crest to crest of perimeter mound. This is the dimengional attribute least likely to change over time, even with lowering and lateral spread of the mound as a result of disturbance.

Spatial relationships and site morphology are both reflective of social and ldeological influences on site location and construction. Environmental influences are equally important, however. Here the relevant factors include sufficient supplies of food and water to support the people gathered at a site; topography suited to the placement and particular uses of these kinds of sites; and soil amenable to site construction. Topography and soil type were determined by plotting site locations on topographic and soil maps, augmented by data collected at the sample of site localities selected for field examination. Proximity to water was determined by measuring the distances from sites to watercourses, billabongs, lakes or any other source of intermittent or permanent water.

Obtaining data on the availability of food in the vicinity of sites was a more difficult task. Aboriginal gatherings and ceremonies often colncided with localized resource abundances (Flood 1980:76,77; Lourandos 1980:250,251; Mulvaney 1976:80; Satterthwait 1987; Sullivan 1977:27-26). Moreover, while engaged in activities at a site, people would have been forced to pursue what Binford (1980:9) terms 'tethered' resource exploitation, exploitation of resources within a day's return travel from a site, especially if site activities extended beyond the period of time for which people could subsist on preserved foods or foods brought with them. 
Given these considerations, proximity of resources to each of the sites in the study population was assessed. Two kinds of situations would have provided adequate quantities of resources: (a) An abundance of resources of only one or two types, supplemented perhaps by much lesser amounts of other foods; or (b) concentrations of a variety of resources, each available in smaller quantities, but which when taken together provide a profusion of foods. Historical accounts suggest that sites located to take advantage of (a) should occur within the environs of such places as bunya (Araucaria bidwill $\underline{i} \underline{i}$ ) scrubs or waterways frequented by seasonal runs of mullet (Mugil cephalus). Sites located with respect to (b) should occur in settings providing access to environmental heterogeneity. Nearness to two or more environmental zones would not only have enabled exploitation of their differing resources, but would also have facilitated access to ecotones, areas of intergradation between distinct ecological communities. Ecotones tend to provide both a concentrated diversity of resources and greater abundances of particular species than occur in adjoining habitats (Odum 1959).

Detecting the presence of environmental boundaries within range of sites posed problems. Nearly a century and a half of extensive land clearance, burning and agriculture has modified or obliterated many preEuropean environments. Where it is impossible to determine the location of ecological transitions, geology provides the best indirect evidence of their former presence. Petrology is a basic determinant of soil type and topography, and hence vegetation (Walter 1973:4-5). As Billings (1970:27) observes, "Among the sharpest biological boundaries are those where different rock types come into contact." On this basis, the distance between each site in the population and the nearest geological boundary was taken as indicative of degree of access to contrasting habitats and their associated ecotones.

Having completed the analysis for the study population of earth circle sites, a control population of equal size was randomly generated and the same analysis applied to it. The results derived from this exercise were then compared to the results obtained for the actual population. This comparison was undertaken as a further check on our conclusions regarding criteria for earth circle location and as a way of ascertaining if the distribution of sites was the product of chance or a manifestation of ordered decision-making processes.

\section{AN EISTORICAL PERSPECTIVE}

Because earth circle sites continued in use well into the last century (e.g. Steele 1984:127,249,250), there are a number of accounts of their function, some of which even relate to earth circles still in existence. These historical accounts provide otherwise unavailable descriptions and impressions of earth circles and their role in Aboriginal life. As McBryde (1979) cautions, however, interpretation of them must be undertaken with care.

The majority of historical accounts divide into three broad categories:

(a) accounts transcribed soon after observation by someore other than the observer (e.g., Pamphlet and Finnegan's accounts recorded by Uniacke and Fraser [in steele 1972:74-83,240,241] and Bracewel1's account recored by Simpson (in Langevad 1979:2]); 
(b) accounts written by the observer but recorded a considerable time after the observations were made (e.g.s Hall (1907]); and

(a) accounts elicited from Aboriginal informants by writers who did not themselves observe earth circles in use (e.g., Donovan [1895] and Mathews [1900, 1910]).

One of the most important accounts, that of Thomas Petrie, falls into all three categories: Petrie's recollections of what he observed and was told were transcribed by his daughter when he was 73 years old (Petrie 1904 ).

The difficulties inherent in asgessing this information are further compounded by the historical context in which it was obtained. Following the establishment of Brisbane in 1825, European expansion in the region proceeded rapidly. By 1844 most of the Moreton Region was subject to pastoral occupation, and by 1860 southeast Queensland was largely divided into properties (Taylor 1967). Although the nature and extent of Aboriginal responses varied, by at least the 1840 s considerable change in Aboriginal life had taken place as a result of geographical displacement, armed conflict and introduced diseases (Langevad 1979; Whal1ey 1987). Consequently, any reconstruction of earth circle ethnography must be taken as representing the situation obtaining in the last century or early in this one, not the situation as it was prior to European incursion.

An additional qualification derives from the cultural significance of the sites themselves. In some cases the activities at earth circles were regarded as secret, and their participants were unwilling to impart information about them (Mathew 1887:166). In other cases, however, details of ceremonies were evidently freely given (e.g., Donovan 1895:1034). There is some indication that what was considered secret varied and that levels of secrecy applied, such that certain kinds of information were readily divulged, while others were not. In any event, none of the accounts consulted deal in other than a speculative manner with the deeper religious or symbolic aspects of ceremonial activity at earth circles.

Although the historical accounts must be treated with caution, they are an invaluable adjunct to data obtained in other ways. The following provides a summary of the information contained in these accounts insofar as it is relevant to the aims of the study. In this regard, what follows is not a comprehensive ethnography, but a problem-guided overview.

\section{Reported Uses of Earth Circle Sites}

With the equivocal exception of a reference to the use of a "circle" at Dugandan for the purpose of a "corroboree" (Hardcastle 1947:22), earth circles in the Moreton Region appear to have been used primarily for resolving disputes and staging initiations.

Dispute settlement. The earliest accounts of earth circle use come from the castaways John Finnegan and Thomas Pamphlet, who, in 1823, separately witnessed the use of earth rings for the purpose of settling disputes between groups of people (Uniake in steele 1972:74,78). The stated reasons for conflict were an injury suffered by an individual at the hands of a member of another "tribe" and an instance of trespass to hunt and fish (Uniake in steele 1972:74; Frager in Steele 1972:240). The offended group 
traveled to the transgressor's country, where the two groups adjourned to a circle to settle the issue (Fraser in steele 1972:240). Fighting was conducted between two individuals within the circle, was apparently formalized and regulated by strict rules, and was not restricted to men, Finnegan having observed a fight between two women (Uniake in steele 1972:74-75,78; see also winterbotham 1983:61-62).

At the fight observed by Finnegan a breach of the rules resulted in a general battle; the opposing groups and their allies moved away from the circle to line up facing each other, and engaged in a fight lasting over two hours (Uniake in steele 1972:79). The fight seen by Pamphlet ended with a reconciliation between the parties, who then engaged in dancing and wrestling matches between "parcels" of boys before joining in a week-long hunting trip (Uniake in steele 1972:75).

It is difficult to determine the veracity of Finnegan's and Pamphlet's accounts. It is possible that they sought to capitalize on their adventures by embelilishing on their experiences. Of particular interest are the circle diameters they specify; these will be discussed later in relation to site morphologies.

Difficulties in evaluating Finnegan's and Pamphlet's accounts aside, there are other indications that earth circles were venues for combat, as well as for dispute settlement by other means. Among these are a brief mention of fights being held in a large circle near Nimbin, New south Wales, just outside the Moreton Region, and the local tradition that an elliptical earth ring near Tamborine village was used for combat (Shirley 1911:104; , West quoted in steele 1984:22). The suggestion that ritualized combat, or "tournaments", took place in the vicinity of, if not actually in, earth circles is contained in the observation of a large group of people gathered at a "battle ground" near the Toorbul Point earth circle site in 1841 (Nique and Hartenstein in steele 1984:170).

An intriguing piece of further information is a notation on "a drawing of an earth circle site attributed to Robert Hoddle, a member of John Oxley's 1824 expedition to Moreton Bay. This notation reads: "Where the natives meet after, a war with adverse tribes to make peace" (Steele 1972:80; 1984:101,102). Unfortunately, although it has been suggested that this site was at Amity Point, North stradbroke Island (steele 1984:100), neither the source of Hoddle's information nor the site's location are known with certainty.

Hoddle's comment is nevertheless interesting in light of information supplied by the escaped convict David Bracewell. While living with Aboriginal people in the wide Bay and northern Moreton areas in the early 18408, Bracewell attended a meeting called a "Toor". (= ring), this on account of "a great circular ditch being dug...for that ceremony" (Simpson in Langevad 1979:2). Of such occasions, Bracewell related that:

These meetings may be called by any tribe, the messengers being dispatched in eviery direction, and are held for the purpose of settling differences which may arise amongst them (simpson in Langevad $1979: 2$ ).

Reference to "a great meeting of the Native Tribes, 13 or 14 in number" (Simpson in Langevad 1979:2) implies a more peaceful method of dispute settlement than fighting. Although the precise manner in which 
disputes were settled at these meetings is not indicated, the place at which they took place was evidently an earth circle.

Places for initiation. Dispute settlement and initiation were not mutually exclusive activities (in fact, Petrie [1904:56] observes that after any gathering the participants "would in the end part well pleased with each other, and excellent friends"), but by far the greatest number of descriptions concern earth circles as initiation places. Although reports vary in detail, and differences between and within regions also seem to have existed, it is possible to present a generalized summary, for which Petrie's (1904:48-55) account serves as the exemplar.

In essence, initiation, or "kipper-making" (Petrie 1904:48), served "the purpose of passing a lad into a certain stage of manhood" (Davis 1861:57). Usually the site of the ceremony consisted of two earth circles, one larger than the other, joined by a pathway (shirley 1911:103). The people who had been invited to attend the ceremony gathered at the larger circle for the commencement of proceedings. Here the public aspects of the ceremony were enacted, both male and female members of the attending groups being present (Petrie 1904:50,51). From the large circle, the initiates were taken via the pathway to the smaller circle, where the secret parts of the ceremony took place in the presence of men and initiates only. When taken down the pathway, the initiates were shown various images and devices constructed and carved a longside the pathway. These illustrated aspects of myth, law and the initiates' responsibilities as men. In the smaller circle, other secret devices were revealed to the boys (Petrie 1904:51).

Two writers who deviate from this generalized description are Meston (1895:89-91) and Donovan (1895:1034), both of whom state that the small ring was used for the public phase of the ceremony and the large $r$ ing for the secret. Not only is this contrary to common sense, which dictates that the large ring would best accommodate the number of people engaged in the public aspects of the ceremony, but Meston (1895:89) supports his description with a reference to Petrie, and Donovan's information was acquired second-hand and published 45 years after the event he describes.

Although it applies to a locality outside the study area, Hal'l's (1907) description of an initiation ceremony held in the Killarney district, southeast of Warwick, is relevant because this form of ceremony may have been practiced in adjacent areas of the 'Moreton Region. Although Hall's account is far from clear, the ceremonial ground apparently consisted of two concentric earth circles. Furthermore, females and other uninitiated individuals were excluded from any part of the ceremony, and the initiates had to show their skill in self-defense against spears, boomerangs and clubs before admittance into the ranks of the initiated.

Finally, an item of information of considerable interest is provided by Willle McKenzie, or Gaiarbu, whose people occupied the rainforest country just north of Brisbane (Winterbotham 1983). According to Gaiarbu, in addition to men having "bora grounds", women had their own "bora ground" from which men and uninitiated women were excluded (Winterbotham 1983:75). Neither the specific nature of the activities that took place there nor the details of the sites used are indicated.

other uses. Although not mentioned in the surviving record of earth circle uses, it is possible that sites served other functions as well. Among these are use as places to which initiated men or women could repair to 
work on artefacts, meet or talk in seclusion from others. Such "men's camps" or "women's camps" are known elsewhere in Australia (e.g., Meggitt 1962:75-76; O'Connell 1979:101), and it it possible that earth circles or their immediate environs were similarly used. Mundane activity of this kind would not as readily attract the attention of European observers as would large-scale gatherings for fights and ceremonies.

\section{Site Construction and Morphology}

Construction methods have a bearing on site location in terms of soil and topographic preferences. After a suitable place was selected, it was cleared of grass and "loose rubbish", the grass being pulled up by the roots (Mathews 1910:105). The circle was then made, according to Petrie (1904:49), by "...the earth being dug from the centre with sharp sticks and stone tomahawks and carried outside [the circle] on small sheets of bark to form a mound or edging round the ring..." Given the tools available, looge soils would have been preferred, and this is indicated by Mathews (1910:105). Other factors receiving mention as important to circle construction are level ground and, in some cases, a secluded or thickly vegetated locality for the secret aspects of the ceremony (Aldridge in Howitt 1904:600; Mathews 1910:105).

Fighting circles. An important consideration is the extent to which the site morphologies resulting from this construction process varied functionally or spatially within the region. With regard to function, the critical question is whether fights and intiations were held at the same or different sites. What is usually taken as typical of earth circle initiation sites in the region is described by petrie (1904:49), who says that the mound around the circle was:

...about two feet $[0.6 \mathrm{~m}]$ high. The circle itgelf was about forty or fifty feet [12-15 m] across, and was quite round. Then a road five feet [ $1.5 \mathrm{~m}$ ] wide was made from the circle, running about six hundred yards $[548 \mathrm{~m}]$ to another small circle, just the same but half the size.

This description appears to be based on the site at samford (steele $1984: 248)$.

Petrie (1904:44,55) is definite in stating that although" fights followed initiations (see also Aldridge [in Howitt 1904] and Mathews [1910]), these fights were held at a separate place, "an open piece of country suitable for a fight". As already discussed, however, there ls evidence of fighting at or in earth circles. In some cases these circles seem to have differed from those used for initiations. For instance, the supposed fighting circle at Tamborine village featured a semicircular path around part of its periphery and, as will be demonstrated later, also contrasted in shape with the circles at initiation sites (shirley 1911: Plate III). Similarly, the circle reportedly used for fights and other activities at Nimbin. was evidently distinct from an initiation site in the same area (steele 1984:21-22).

According to Pamphlet, the fighting circle he saw was a small ring "...about twenty-five feet [7.6 m] in diameter, about three feet [1 m] deep, and surrounded by a palisade of sticks" (Uniake in steele 1972:74). The diameter of this ring seems small for a fight, given that the spears 
used were clearly thrown by the men at one another, not used for closerange "punishment" spearing (cf. Berndt 1977:347), and could have been up to $3 \mathrm{~m}$ long (Lockyer in steele 1975:41). This augge日ta very close combat and conflicts with Petrie's (1904:44-47) description of spear fights at a distance of 18 to $28 \mathrm{~m}$, as well as with figures of $45 \mathrm{~m}$ for the diameter of the Nimbin circle and $24.3 \mathrm{~m}$ for the length of the elliptical ring at Tamborine Village (Shirley 1911:104; West in steele 1984:22).

Internal consistency lends credence to Pamphlet's account, however. As a preliminary to the fight, the two adversaries "laid down their spears in opposite rows, point to point" (Uniake in steele 1972:74). The sum of the lengths of two, spears laid "point to point" would have approximated the stated diameter of the circle. A further statement in the account does suggest close combat indeed; a spear thrown by one of the combatants penetrated "three or four inches" (75-100 mm) into the shield of the other (Uniake in steele 1972:75), as would be expected if cast at close range. Finally, one type of spear was made specifically for use in close quarter fighting, "as it was too long and heavy to throw far" (Petrie 1904:102).

Although the circle diameter cited by Pamphlet is within the range of diameters given by petrie for the smaller of the two circles at an initiation site, there is no mention of a pathway, and the circle was said to be surrounded by a palisade of sticks, a feature at odds with descriptions of initiation sites.

In contrast to these cases, other circles appear to have been used for both fighting and initiation. The fighting circle seen by Finnegan was "a circular pit" $12.2 \mathrm{~m}$ in diameter (Uniake in steele-1982:78). Furthermore, "...the picked men on both sides, being armed, entered the pathway and marched into the circle" (Fraser in steele 1972:241; emphasis added). Finnegan's description is recounted by Fraser who, to corroborate Finnegan's account, details a "battle circle" he (Fraser) had encountered south of Brisbane:

It consisted of an enclosure thirty-three yards [30.2m] in circumference, edged by a path three feet [Im] broad and ten inches [0.25m] deep, from which another path of similar dimensions diverges in a direct line, frequently [sic] for half a mile [800m] in length (Fraser in steele 1972:240; emphasis added).

The diameters of these circles and the presence of pathways indicate that they were initiation sites.

Also likely to have been used for initiation, as well as resolving disputes, is the "Toor", the "great circular ditch" for "settling differences", reported by Bracewell (Simpson in Langevad 1979:2). This site was seen in either the northern Moreton or the Wide Bay areas, and it is revealing that "Dhur" and "Tur", meaning "circle", are terms said to have been used in these districts for the larger circle of an initiation site (Mathew 1910:97,98; Petrie 1904:48).

If these accounts accurately reflect the historical situation, then there appears to have been considerable diversity in the kinds of dispute settlement procedures employed, the kinds of sites used for this purpose, the number of participants, supporters and onlookers present, and the relationship between dispute settlement and initiations or other 
ceremonies. All of this indicates a complex political life and an equally complex relationship between political activity and earth circle sites. Regrettably, the surviving record is insufficient to unravel all of the details. It does; however, suggest that some sites were used for both dispute settlement and initiation, while others were used only for the former.

Initiation sites. Equally difficult to resolve with certainty is the extent of spatial variation in the morphology of initiation sites. Because they may have extended into the Moreton Region, accounta relating to initiation sites in adjacent regions are relevant, and of interest in this regard is the "Dora" ceremonial ground described by Aldridge (in Howitt 1904:600). This ceremony was practiced in the Maryborough district and took place at a site consisting of "a circle of logs and earth about four feet [ $1.2 \mathrm{~m}] \mathrm{high}$ and fifteen inches [0.4 m]. wide at the top". circles ranged from 5.5 to $23.0 \mathrm{~m}$ in diameter. From the circle, a pathway of "not more than two or three hundred yards [183-274 m]" length led to a cleared patch in the scrub where the secret aspects of the ceremony took place. This cleared area in dense vegetation is the obvious counterpart of the second, smaller circle used in other areas.

The best source against which to assess Aldridge's information is Mathew (1910:97-109). Curiously, the two accounts are quite different. Mathew's information relates to Kabi Kabi and Waka Waka peoples of the Maryborough district. When discussing the initiation ceremony practiced by these peoples, Mathew (1910:105) refers to the "large circle" of the initiation site, implying that there was also a small circle, contrary to Aldridge's account. The absence of any similarity of Aboriginal terms or ceremonial procedure between the two accounts leads to the conclusion that the two men observed or elicited information about two different ceremonies. Since at least one of the ceremonies observed by Aldridge (in Howitt 1904:606) occurred "on the mainland opposite Frazer's [sic] Island", while Mathew's information most likely concerns the Burnett River district, where he lived on a station (Australian Encyclopaedia 1965:9), the differences in the two descriptions probably reflect differences in the ceremonial sites of inland and coastal peoples.

Initiation ceremonies that Howitt (1904:606,607) regarded as "generally similar" to the Dora were performed to the south of the latter. Howitt refers to these as "Kaiabara ceremonies", the name being derived from a group living to the northwest of the Moreton Region. It appears, however, that only a single ring was constructed, and there is no mention of a pathway. Furthermore, a hole was dug in the centre of the ring for the purpose of concealing an old man under a piece of bark.

Moving further south into the northern part of the Moreton Region itself, Winterbotham (1983:77) reports that the "Jinibara" of the upper Brisbane Valley constructed initiation sites consisting of two circles, one large and one small, as in Petrie's account. The distance between the two was usually about $90 \mathrm{~m}$, and the larger circle was placed to the north of the smaller. This orientation was mandated by the alignment of two dark patches in the Milky Way which represented mythical sky Bora Rings.

Mathews (1910:103) contends that a ceremony called the "Toara" was practiced in southern Queensland from the border with New south wales to Port Curtis and inland for a distance of 240 to $320 \mathrm{~km}$. Mathews' description of the site associated with this ceremony is generally similar 
to the initiation site described by Petrie (1904:49). Around cileared ground:

...small logs and sticks are laid horizontally, in the form of a circle, and are covered with loose earth, making a low wall about 18 inches [ $0.45 \mathrm{~m}$ ] high. The circular space thus enclosed ranges from 50 to 100 feet $[15-30 \mathrm{~m}]$ in diameter...about a quarter or half a mile [400-600 m] away, the distance depending on the character of the country, another round space...is cleared and enclosed in the same manner....A small opening is left in the bounding wall of either [?each] circle, and a narrow path...leads through the forest from one to the other (Mathews 1910:105).

In contrast to most reports, which often focus on the exotic and spectacular, Mathews' $(1900,1910)$ accounts provide a valuable detailed overview of the ceremony. This detail, together with the many Aboriginal terms for parts of the ceremony and the physical structures associated with it, suggests the work of a sophisticated investigator (see McBryde $1974 b: 225$ ).

Nevertheless, there are some obvious shortcomings in Mathews' descriptions. For instance, he does not indicate that there was any difference in diameter between the two circles, when other writers make a definite distinction between them. Given the other evidence available, it also seems unlikely that the type of initiation site he describes was used over the large geographical area he specifies. Finally, although they agree in general, there are some marked discrepancies between the accounts of Mathews and Petrie. Both indicate that initiation was a two-stage ceremonial procedure, with only one stage taking place at an earth circle site. However, while Petrie (1904:48) states that the second and "greater ceremony" was staged at an earth circle site, Mathews (1910:103) says that only the "preliminary" ceremony was held at these places. The difference may reflect the fact that Mathews' information represents the recollections of old men recorded early in this century, some considerable time after Petrie's information was obtained. Another possibility is that Mathews' and Petrie's accounts may relate to different areas within the region. Lastly, Mathews may have extrapolated, in part at least, from northern New south wales, the area with which he was most familiar. An indication of this is contained in his comment that tooth avulsion was practiced in the Moreton Region (Mathews 1900:142), when it was not (Howitt 1904:583).

Relevant to the southern and southwestern portions of the Moreton Region are another account in Howitt (1904) and Hall's (1907) description of initiation in the Killarney area. Howitt (1904:578-583) describes the uge of a "large circle", constructed in addition to a "Bora circle", for the final stages of the initiation ceremony practiced by the "Chepara Tribe" of the southern Moreton coast. Apart from use of a second, separate earth circle site, other features of the ceremony accord with the ceremonies more usually described for the region. Ambiguity in the account makes it difficult to determine if it refers to a single-ring initiation site or is a loose reference to the "two-rings-and-a-path" site type. Some support for the former interpretation is provided by Gresty's (1947:63) brief reference to what could be single-ring initiation sites in the nearby Numinbah Valley. At any rate, Howitt's information is of uncertain authorship and there are no other accounts dealing with the same people or ceremony. 
Hall (1907) describes the initiation ground used in the Killarney district as including a "covered in avenue", of unspecified length, leading to an earth structure of which:

The centre ring was about thirty feet $[9 \mathrm{~m}$ ] in diameter with poles driven in five or six feet [1.5-1.8 m] apart, and about seven feet [ $2 \mathrm{~m}$ ] high, with their tops all bound around with titree bark about the size of a man's head. These poles represented the number of young men that were to pass through the Bora ceremonies.

The centre ring was formed the same as a circus ring, only they had an outside ring about eight feet [2.4 $\mathrm{m}$ ] wide. The kippas all stood in the outside ring, each youth alongside his own pole. The King and his councilors stood in the centre ring....

Opposite every post around the outside of the circle was a clear track cut in the scrub forty yards [37 m] long.

This description appears to refer to a site consisting of two concentric circles from which radiated a variable number of separate trackways. Unfortunately for the purpose of archaeological identification of such sites, it is unclear, except for the poles around the inner circle, how the circles were physically delimited.

Any attempt to reconstruct the 19th century distribution of the various kinds of initiation sites on the basis of historical accounts is bound to be constrained by the nature of the sources employed. For instance, much of the available information is localized, and in many cases it is uncertain how widely a particular type was distributed. A further limitation is that the evidence for some site types is provided by only a single source, the accuracy of which, without corroborating evidence, can only be taken at face value.

These difficulties aside, a reconstruction of site type distributions is presented in Figure 2. In general, initiation sites divide into two major morphological types: those with two rings joined" by a path and those with a single ring. It seems that groups in the northern Moreton Region used sites of the former type, although single-circle sites may have been constructed in the extreme northern and northwestern districts. Historical accounts also suggest that single-ring sites may have been used in the southern part of the region, especially. in the more southerly and southwesterly portions. Sources generally agree that earth circles were made by heaping up soil to form a perimeter mound around a circular area. To the north of the region, logs were incorporated into the mound, although Mathews, in a questionable generalization, extends this to all of southeast Queensland.

\section{Social and Economic Concomitants of Circle Use}

Historical accounts provide some information on social and economic factors that might have influenced site distribution and location. These include the size and duration of gatherings at earth circles, the scheduling and provisioning requirements of gatherings, and the prevalence of sites in the region. 

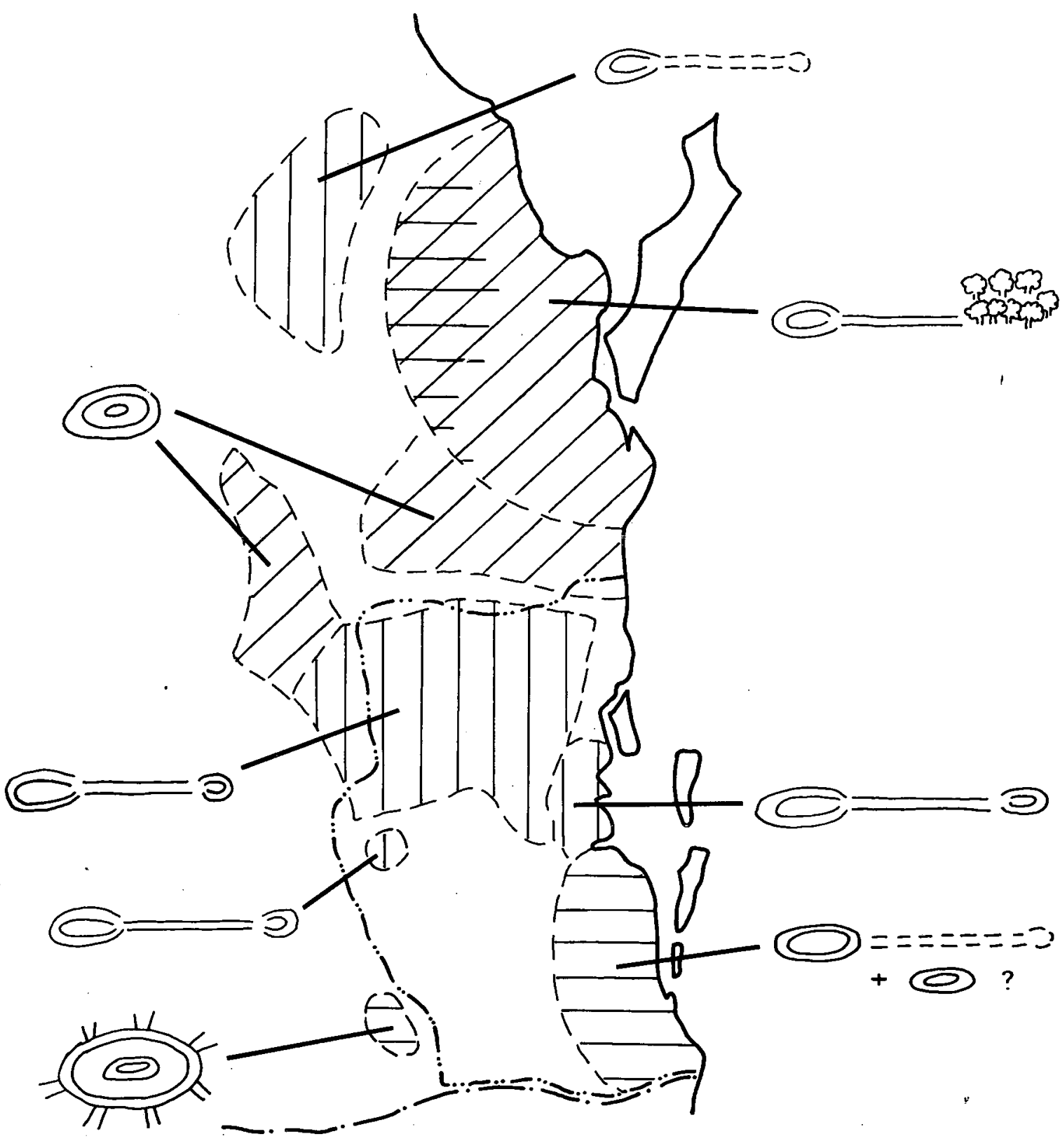

Figure 2. Distribution of site morphologies in the Moreton and adjacent regions as inferred from historical accounts (horizontal hatching = morphology uncertain; vertical hatching = double ring sites; diagonal hatching = single ring sites). 
Size and duration of qatherings. The number of people assembled for dispute settlement or initiations could be substantial. Finnegan (Uniake in steele 1972:78) reported that the huts of the people gathered at the fight he attended "were so numerous I could hardly count them". Some 500 people were evidently present at the fight observed by Pamphlet (Uniake in Steele 1972:74), and Nique and Hartenstein (in Steele 1984:170) report 2000 men, women and children assembled for the fight at Toorbul point. Bracewell spoke of 13 or 14 tribes gathered at his "great meeting" (Simpson in Langevad 1979:2). What kind of social unit these "tribes" represent is unknown, but estimates of their size range from 60 to 150 people (Whalley 1987:16). If the conservative figure of 60 is used, then this gathering consisted of between 780 and 840 people. Initiations could involve equally large numbers: estimates of size range up to 3000 people (Aldridge in Howitt 1904:606), but Sullivan (1977:35-36) suggests 1000 people as a more likely maximum.

Activities at the earth circles to which Finnegan and Pamphlet were taken lasted for two or three days (Uniake in steele 1972:74-75,78-82). According to Mathews (1910:106), the arrival of the various groups at a Toara initiation was timed so that all arrived within a few days of one another. Once this occurred, activity at the earth circle site lasted about a day and a half, after which the men and initiates separated from the women to travel through the bush, hunting and camping in different places for "some days, or the better part of a week" (Mathews 1910:110). This period of bush travel terminated with several days of further ceremonial, a reuniting with the women and "sham fighting" with the "poopoon", a party of men from a distant group who acted as adversaries in ritual combat (Mathews 1910:111-114). Aldridge's account of initiations is similar. It seems that the participants met at a campsite and waited there until all were assembled prior to moving to the initiation site (Aldridge in Howitt 1904:602). Aldridge (in Howitt 1904:603-604) also gives the impression that ceremonial activity at the site was not protracted and, as in Mathews' Toara, finished with the men and initiates moving off separately from the women and children before reuniting with them at a later time.

These accounts indicate that the time spent at fights or at an initiation site was relatively short, although much more time might be spent traveling through the surrounding area as part of the ceremony. This contrasts markedly, however, with other descriptions. Petrie $(1904: 50,54)$ states that the host group for an initiation might camp and hunt near the site for two or three weeks while waiting for all the invited groups to arrive and that once it commenced, ceremonial activity at the site occupied as much or more time again. Mathew (1910:98-106) likewise indicates that initiation activities at and in the immediate vicinity of the site might last up to a month, although a shorter ceremony of only about a week was also practiced.

Provisioning requirements. Up to 1000 people gathered at a given place for even a few days can greatly tax local resources, and there is evidence that this was a consideration in the scheduling of ceremonies and the selection of site locations. For instance, Howitt (1904:595) says of the "Turrbul", people who "occupied country on the Brisbane River", that initiations were held when there was a seasonal abundance of such resources as mullet or the seeds of bunya pines. Mullet are present in the greatest numbers when migrating schools make their way through Moreton Bay between April and July of each year (Welsby 1967:85). Bunya nuts are available annually in 
January and February, but some years provide a much greater yield than others because the tree has a crop interval of two to three years (Walters $1974: 224$ ).

The advantages of timing ceremonies to coincide with a superabundance of sea mullet (cf. Hall 1982:82) or bunya nuts is obvious. More subtle is the scheduling that Winterbotham (1983) indicates was employed by the Jinibara. These people reportedly held initiations only when the mythological Bora rings in the night sky, "two dark (black) spaces (circles)--the 'coal sacks'--in the heavens", were in the proper northsouth orientation (Winterbotham 1983:77). The "'coal sacks" referred to here are undoubtedly the two dark spaces in the Milky Way close to the Southern Cross, one of which is commonly known as the coalsack (Norton and Inglis 1966:11). If so, this section of the Milky way is in north-south orientation early in the evenings of March-April and september-october, depending on which other dark space is considered to be the second Sky Bora Ring.

That an inland people would use this particular celestial event as a criterion for the scheduling of ceremonies is significant in light of Lilley's (1982, 1984) "pulsation" model for Aboriginal settlement and subsistence in subcoastal southeast queensland. The model postulates that subcoastal peoples followed "a subsistence-settlement strategy of cyclical aggregation and dispersal" in accord with the seasonal dichotomy of dry winters and wet summers that characterizes the Moreton Region (Lilley 1984:27). In winter (April-September), populations would have aggregated in "large extrafamilial base camps" near major watercourses and lakes where water and food resources are obtainable. In summer (October-March), populations would have dispersed into smaller, more mobile residential and production units to exploit upland resources and the non-perennial water supplies that become available at this time of the year (Lilley 1984:27).

The import of either March-April or September-october as the time for initiations is that these times bracket the summer and winter seasons and articulate with the economic and social facets of the pulsation model. March and october are the times of peak availability of commonly used plant foods in all of the major biotic communities of the subcoastal area (Lilley 1984:Figure 3). Furthermore, as periods of high primary productivity, these would also be times of greater general availability of those animal resources subject to capture by technological means (e.g., cooperative net hunts) that can generate large immediate surpluses (cf. Satterthwait 1987).

of the two periods, however, March-April, and especially March, is likely to have been the preferred. If meteorological records for Brisbane are any guide, March is the third wettest month of the year and receives on average nearly three times as much rain as september (which also tends to be the second driest month of the year) and twice as much rain as october (Bureau of Meteorology 1977:11). (Importantly, January and February, the months when bunya nuts can be harvested, are also the two wettest months; the ready availability of water at this time would have assisted inland travel to this special resource.) In addition, the september-october period comes at the end of the winter dry season and is when major watercourses, and presumably their tributaries, experience the lowest flow volumes (Lilley 1984:Figure 2). In contrast, March-April occurs at the end of the wet season, when both permanent and non-permanent water supplies have been replenished by several months of frequent precipitation. 
There seems, then, to have been an underlying economic rationale for holding ceremonies in this area when the coalsack was in proper position. Equally important is that the staging of ceremonial gatherings at this time also accords with the social implications of the pulsation model. The March-April period is one of abrupt environmental changeg-during this period rainfall declines by some $40 \%$, the range of available plant resources falls sharply in all major floristic communities, and stream flows drop markedly (Bureau of Meteorology 1977:11; Lilley 1984:Figures $2,3)$. Consequently this also would have been a time of transition from dispersed to aggregated population distribution as people began to cluster around permanent water. The gathering of people for initiations in MarchApril would have marked this social transition with an extraordinary event, provided a mechanism for bringing previously dispersed people together, allowed for the exchange of information on the location of suitable winter base camps, and facilitated the political process of aligning people into winter residential commlinities (see Riches [1982:43] for a parallel situation among arctic hunters). Given this, the paucity of references in the historical literature to winter gatherings is probably a reflection of social and economic scheduling requirements and not necessarily, as sullivan (1977:53) suggests, a result of incomplete records.

No matter at what time fights or initiations were held, however, their spatial location in relation to resources was also a critical consideration. Finnegan reported (Uniake in Steele 1972:77-78) that the group he accompanied to a fight took fern roots and nets, and that the morning after they arrived at the battle circle, "a large party...went out kangaroo hunting". Mathews (1910:104-105) states that the hosts of an initiation ceremony selected:

...a suitable locality in their own territory, near some creek or permanent waterhole, where game and other foods are sufficiently plentiful to support the people while the ceremonies last.

Furthermore, the host group camped 32 to $48 \mathrm{~km}$ away while "only a few men" went to prepare the site for the ceremony, this "in order to prevent the natural food,supply from being drawn upon any more than is unavoidable" (Mathews 1910:105). Arranging the arrival of attending groups so that all appeared within a few days of one another would also have assisted the conservation of resources, as would the separation into smaller parties and travel that followed ceremonial activity at the site (Mathews 1910:109; sulivan 1977:55).

In light of these efforts to conserve local resources, it is interesting that Mathews' account contrasts at so many points with that of Petrie. As noted, according to petrie the host group might camp and hunt near the site (in fact only $185 \mathrm{~m}$ away) for several weeks prior to the ceremony; ceremonial activity at the site lasted for a further several weeks; and, other than the movement of the whole gathering to another place for the concluding ritual battle, there is no mention of travel through the surrounding countryside as part of the ceremony.

These differences may reflect the impact of European incursion on the conduct of Aboriginal ceremonial life, but another possibility (not necessarily unrelated if colonization compelled larger, less mobile aggregations at fewer sites) is that petrie's description has greater relevance to coastal than to inland parts of the region. The very high fecundity of Moreton Bay and adjacent coastal areas was such that high 
population densities and limited mobility could be supported for longer periods of time in this part of the region (Hall 1982:79-87). This of course does not obviate the importance of resource availability in the selection of site locations--it simply indicates that judicious site selection in a more productive environment would have al lowed gatherings of larger size and longer duration than would have been the case in less productive environments (Sullivan 1977:59).

Frequency of site occurrence. Historical accounts provide some insight into the factors affecting the prevalence of sites in the region. Petrie (1904:55) states, for instance, that "the [A]borigines did not each time make fresh rings, but there were certain ones that different blacks always used, and these they would fix up". Mathews $(1910: 105,114)$ comments that "The hosts always had a toara ground in their own territory..." and that usually "...the same ground was used for many years, being renovated every time a toara was held there". Similarly, according to winterbotham (1983:77) initiation sites were "always well looked after" and the location of them "was never altered".

This indicates that earth circle sites were associated with particular kinds of social groupings, that new sites were not often constructed, and that initiation sites were curated and remained in use for a considerable period of time. If it is also true that sites disappeared relatively soon after abandonment, then the ratio of abandoned sites to sites in use would have been small, and the number of sites in the region at any one time would have been determined primarily by the number of circle-making social units present. Neither the nature nor the number of these social units is specified, but Mathews' and Winterbotham's comments imply that they were also land-holding units, possibly clans (cf. Whalley 1987:32). However, the number of known sites alone is much greater than the number of "tribes" or "clans" posited to occupy the region (see whalley 1987:Appendix A). Either each social unit laid claim to a number of such sites (e.g., Winterbotham 1983:77), sites were associated with social groupings of a different kind or, as has been recently argued (Butlin 1983:145; Whalley 1987:14), the size of the region's Aboriginal population was much larger than has generally been acknowledged.

Yet another factor has a bearing on site numbers. It seems that initiations rotated among sites. The location of a given initiation ceremony "...depended on which tribe had the most boys ready for the ceremony, and did the inviting. If a coast tribe invited, then all the others went to the ring that tribe would naturally use, and so on" (Petrie 1904:55). Likewise, according to Mathews (1910:114), "The custom was that the people who were the poopoon at one toara should be the hosts at the next, and that one of the other mobs should take the duty of being poopoon." The ceremony was always staged at the host's initiation ground, while the group residing farthest away from that point assumed the role of poopoon.

No doubt this circulation of ceremonies among sites had important social and ideological underpinnings, but as Sullivan (1977:55) stresses, it would also have been a matter of ecological necessity. Large numbers of people gathered for ceremonial activity would exhaust local resources and preclude the reuse of a site without a considerable period (up to three or four years [Sullivan 1977:49,55]) of resource regeneration. As a result, the holding of initiations at suitable intervals would have required the rotation of ceremonies among sites-and a sufficient number of sites to enable doing so. 


\section{ARCHAEOLOGICAL DATA: ANALYSIS AND RESULTS}

As useful as it is, the historical literature obviously provides only a partial view of the various sociocultural and ecological associations of earth circle sites. A more complete picture emerges when this literature is balanced against the perspective available from examination of the tangible evidence of existing earth circles and earth circle localities.

\section{Site Distribution and Spatial Relationships}

One matter on which historical accounts are largely gilent is site distribution. An important observation in this regard is that known earth circle locations are differentially distributed in the Moreton Region. For example, $87 \%$ of sites occur in places at or below $150 \mathrm{~m}$ in elevation (Table 2), and 698 of sites occur in only two of the region's five major physiographic subregions (Table 3). Moreover, 858 of sites occur to the east of a line extending from Moore through Ipswich to Beaudesert (a line which also parallels most of the length of the Brisbane River), and the highest site densities are found in the basin of the South Pine River, the lower reaches of the Brisbane River and the D'Aguilar Range area between Dayboro and Somerset Dam.

Table 2. Elevation above mean sea level.

\begin{tabular}{rcc}
\hline ELEVATION $(\mathrm{m})$ & $\begin{array}{c}\text { NUMBER OF SITES } \\
(N=62)\end{array}$ & $\begin{array}{c}\text { PERCENTAGE OF SITES } \\
\end{array}$ \\
\hline $0-50$ & 30 & 48.48 \\
$51-100$ & 18 & 29.08 \\
$101-150$ & 6 & 9.78 \\
$151-200$ & 2 & 3.28 \\
$201-250$ & 0 & - \\
$251-300$ & 0 & - \\
$301-350$ & 0 & - \\
$351-400$ & 1 & 1.68 \\
$401-450$ & 1 & - \\
$451-500$ & 0 & - \\
$501-550$ & 0 & 6.58 \\
$551-600$ & 4 & \\
\hline
\end{tabular}

Table 3. Site distribution in relation to physiography.

\begin{tabular}{lcc}
\hline $\begin{array}{l}\text { PHYSIOGRAPHIC } \\
\text { SUBREGION* }\end{array}$ & $\begin{array}{c}\text { NUMBER OF SITES } \\
(\mathrm{N}=62)\end{array}$ & PERCENTAGE OF SITES \\
\hline Offshore Islands & 4 & 6.58 \\
Coastal Lowlands & 23 & 37.18 \\
Subcoastal Lowlands & 10 & 16.18 \\
Subcoastal Highlands & 20 & 32.38 \\
Western Escarpment & 5 & 8.18
\end{tabular}

* Source: Co-ordinator General's Department 1972 
It is doubtful that a factor such as altitude figured directly in the selection of earth circle locations. It is more likely that altitude, physiography and easterly location link with other environmental and social factors that were taken into account when site locations were determined. The environmental parameters of site location are examined in detail in a later section, but a significant further consideration is that the differential distribution of sites in the Moreton Region mirrors the differential distribution of the Aboriginal population. The large proportion of sites situated in the more easterly part of the region accords with early reports that some $60 \%$ of the Aboriginal population of Southeast queensland lived along the seacoast (Simpson in langevad $1979: 12,13)$.

An important distributional attribute is the extent to which site locations exhibit a clustered, random or uniform distribution. This was assessed by means of nearest-neighbour analysis (Clark and Evans 1954; Hammond and MCCullagh 1974). Tominimize the influence of island sites that could be extraneous to mainland distribution patterns, earth circles on North stradbroke, Moreton and Bribie Islands were excluded from the analysis, as were sites not, in the strictest sense, earth circles (i.e., sites with no raised perimeter mound). The resulting set of 53 sites exhibits a nearest-neighbour index $(\underline{R})$ of 1.13 , a figure marginally above 1. the value characterizing a random distribution. Although site densities in some parts of the region might be higher than in other parts, the fact that $\underline{R}>1$ indicates that there is no clearly defined clustering of sites, as would be expected if sites were concentrated, for example, at coastal or riverine locations.

It is possible, however, that the size of the Moreton Region and certain characteristics of the study population obscure the picture. For instance, this kind of analysis tends to average out subregional distribution patterns, thus masking localized departures from "randomness". It is also possible that sites were not randomly placed, but were associated with other factors that were distributed in this way (Hammond and McCullagh 1974:241). Finally, the index figure derived is influenced by the areal extent of the region considered; in particular, the inclusion of subregions in which sites do not occur can significantly alter the result (Hsu and Tiedemann 1968).

One way of circumventing these problems is to reduce the scale of analysis. This was achieved by focusing on site distribution in the northern Moreton coast and hinterland only (Mt. Coolum to Toorbul Point and inland for a distance of $35 \mathrm{~km}$, an area of $10,000 \mathrm{~km}^{2}$ ). The North Coast was selected because its present-day site density and distribution may approximate the past situation and because it does not contain the large tracts of land devoid of sites that distort nearest-neighbour indices. Analysis resulted in an index of 1.66 , implying a regular (nonrandom) distribution of sites. If the present-day distribution of sites on the North Coast is indicative of the original distribution, then it is possible that other areas also tended toward regular distribution of sites prior to European colonization and subsequent site destruction.

Another way of dealing with the difficulties noted above is not to decrease the scale of analysis, but to increase it. This can be achieved by including in the nearest-neighbour calculation more distant neighbouring sites, a procedure which, as Hodder and orton (1976:41) observe, "is important because it allows determination of pattern at more than the most 
detailed scale". Accordingly, measurements were made to the five nearest neighbours of each site, resulting in a nearest-neighbour index of 2.09 . The high value of this figure must be accepted with caution, however, because the "edge effect" produced by sites next to the region's boundaries can produce a misleadingly large index (Hodder and orton 1976:41-42). Nevertheless, the figure is high enough to reinforce the North coast subregional result and suggest a strong tendency toward regular site distribution.

This trend toward regular distribution is manifested at the level of individual sites. in terms of the high frequency with which sites are bounded by two or more other sites an equal distance away, a relationship that often extends to several sets of sites at differing distances. The site at Woodford (KC:A45) is a good example of this. Among the 22 other sites within $40 \mathrm{~km}$ of this earth circle are two sites at $18 \mathrm{~km}$, a further two at $24 \mathrm{~km}$, two again at $26 \mathrm{~km}$, three at $31 \mathrm{~km}$, three at $37 \mathrm{~km}$, and two at $40 \mathrm{~km}$. Overall, 718 of the sites in the population are associated in this way with between 3 and 14 other sites at varying distances, and if the tolerance of measurement were increased to equidistant within $\pm 1 \mathrm{~km}$, this figure would be considerably higher (in the case of the woodford site, for example, it would rise to 21 out of the 22 surrounding sites). Consequently, although there is no universal spacing distance between the sites in the region, it seems that the majority of sites do exhibit patterned spatial relationships, on an individual basis, with surrounding sites.

It is possible, of course, that this pattern is the result of fortuitous site destruction and preservation. It is very unlikely, however, that site destruction was patterned to the extent that it would convert a random distribution of sites into a regular one. More likely is the converse -- random site destruction converting a nonrandom distribution into a random one (Hodder and orton 1976:54).

At any rate, the results of this analysis indicate that a degree of "competition" obtained among sites, that the placement of sites inclose proximity to one another was avoided (cf. Hodder and Orton 1976:55). There undoubtedly were several reasons for this, but an important factor is that sites too closely spaced would have drawn on the same set of resources. It is possible to arrive at some idea of how far people might have traveled from a site in the course of obtaining food and water. Evidently the lKung san tend to range no further than about $9.7 \mathrm{~km}$ on single-day hunting and gathering excursions (Lee 1969:67). In the Western Desert, a one-way journey of approximately $15 \mathrm{~km}$ was regarded as a normal day's travel (Tindale 1978:153), while suliivan (1977:36) calculates that Thomas Petrie traveled some $16 \mathrm{~km}$ a day when accompanying a group of Aboriginal people on a trip to the Blackall Range. Given this information, and the fact that foraging excursions out and back from a given site would probably involve less daily travel than would a directed journey to a distant destination, then $10 \mathrm{~km}$ is a reasonable estimate of the return distance generally traveled from a site to obtain resources.

In this regard it is significant that the mean distance between nearest-neighbour sites in the population is $11.4 \mathrm{~km}$. A $10 \mathrm{~km} \mathrm{return}$ journey while seeking resources would entail travel of no more than $5 \mathrm{~km}$ from a site, and $11 \mathrm{~km}$ is close to the minimal distance that would avoid overlapping foraging zones around adjacent earth circles. Furthermore, distances above or below the $11 \mathrm{~km}$ mean should correlate with lesser or 
greater resource densities near sites, longer or shorter foraging radii from sites and differences in the amount of time actually spent at sites in conjunction with dispute settlement or ceremonial proceedings.

\section{Site Morphology}

Other distributional and locational patterns appear when the morphological variation among sites is taken into account. However, while analysis of some site attributes only requires knowledge of site location, detailed information derived from examination of extant sites is often necessary for morphological analysis. For this reason, some of the following analysis drew on data for only part of the Moreton Region earth circle population, in particular, 22 sites measured by J.G. Steele (Archaeology Branch site records; 1984), supplemented by a further 4 sites in the field study sample measured by using the same set of procedures. Dimensional data available from other sources were not included because their measuring methods were unspecified and may not have produced measurements comparable to those of the principal sources.

Grosg morphologyy. Sites may be divided into several morphological categories on the basis of number of rings, presence or absence of a pathway and form of perimeter mound, if indeed one is apparent. As Table 4 shows, morphological variation, even at this general level, is considerable; in fact, the range of morphologies present in the site population is even greater than that indicated in historical accounts. Nevertheless, two categories -- sites consisting of either two circles and a pathway or a single circle - account for over 608 of the sites in the population. These are the types of sites most frequently referred to in the historical literature.

Table 4. Gross moxphologies of earth circle sites.

MORPHOLOGICAL CATEGORY

NUMBER OF SITES

$(\mathrm{N}=62)$

A. Three Earth Circles Joined by a Pathway

1

1.68

B. Two Earth Circles Joined by a Pathway

c. One Earth circle and a Pathway

6

F. Other Morphologies one earth circle and one stone circle (1)

two concentric earth circles (1) flat, smooth areas (1) bare earth circles

D. Two Earth Circles

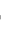

F. Morphology Unknown or Equivocal 
Table 4 is a summary of present and reported site morphologies. A major concern, however, is the extent to which existing morphology represents past morphology and the degree to which differential preservation has resulted in both the morphologies shown in the table and their frequencies of occurrence. The possible morphologies resulting from differing degrees of site degradation are shown in Table 5. It should be stressed that the possibilities indicated are idealized. Pathways, for instance, are the site component most vulnerable to destruction (or to being overlooked), and while there are extant sites consisting of circles without pathways, there are no reports of pathways without circles. At any rate, as the table indicates, it is possible to derive most of the other site types from partial destruction of sites containing three circles and a pathway. If this were commonly the case, however, sites of this type should be reported in the historical literature, when they are not, and more of them than the one known example should occur in the region. More probable is that the site types "2 rings + path", "1 ring + path" and "1 ring" have resulted from varying degrees of preservation (or incomplete recording) of either "2 rings + path" or "1 ring + path" site types.

Table 5. Morphologies resulting from differential destruction of site components.

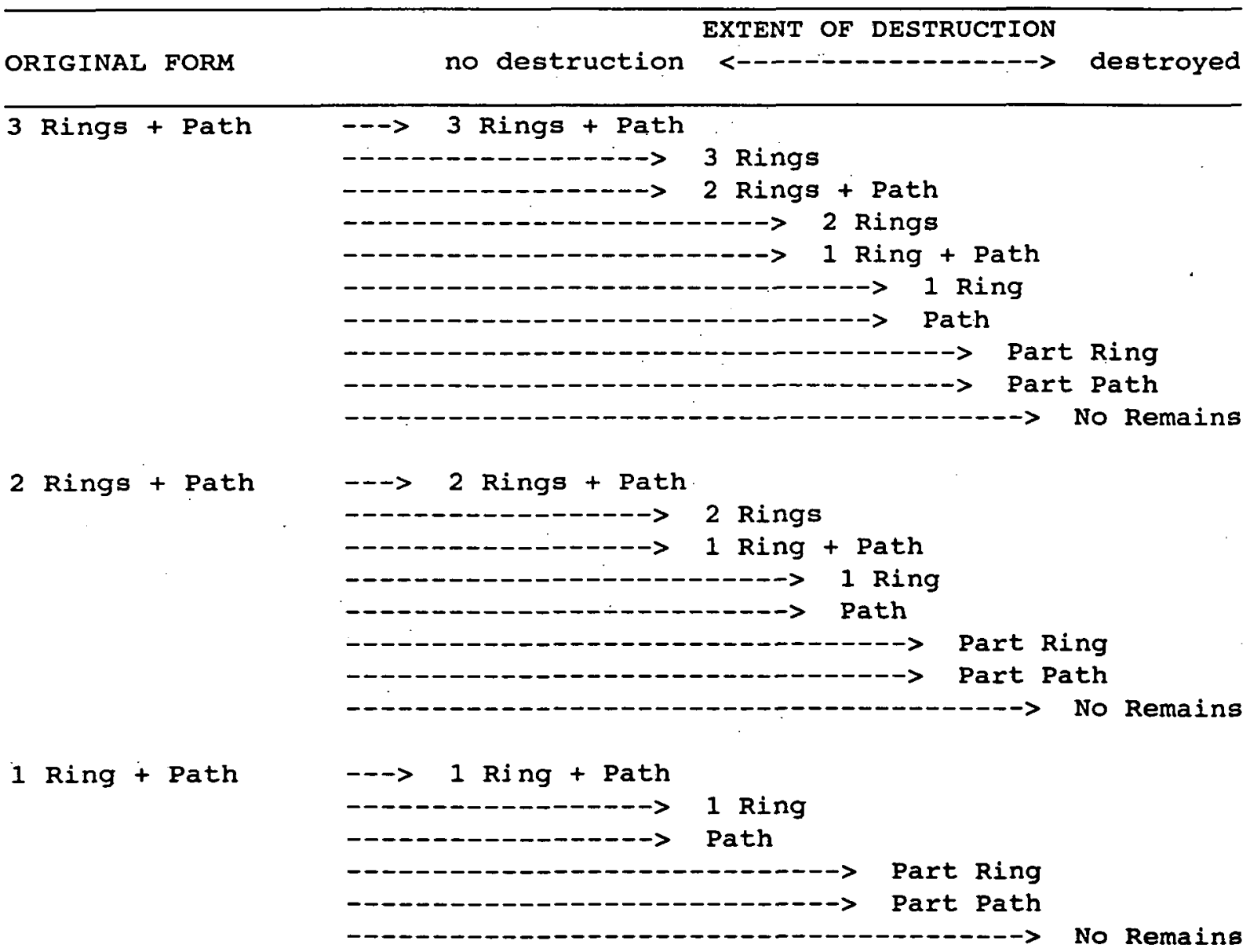

1 Ring

--> 1 Ring


Dimensional attributes. The problem of drawing more accurate morphological distinctions between sites requires a more detailed look at their attributes, especially those relating to ring size, shape and orientation. "Averaged ring diameter" is a concept applied by steele (1984:28) to refer to the average of the lengths of the long and short axes of an earth circle. In order to standardize method, measurements are taken from crest to crest of the perimeter mound at the eight major points of the compass (N-S, E-W, NE-SW, NW-SE). The averaged ring diameters of the 26 sites for which comparable measurements were available range from 10.5 to $29.8 \mathrm{~m}$. circles known to be the smaller of a pair range from 10.5 to $15.5 \mathrm{~m}$ in averaged diameter, while those identified as large circles have diameters ranging from 19.0 to $29.8 \mathrm{~m}$. The 11 gingle rings not known to be the surviving small or large circles of multiple circle sites vary from 11.6 to $24.9 \mathrm{~m}$ in averaged diameter. Two of these single rings fall within the size range of known small circles, 5 fall within the range of large circles, and 4 possess diameters falling between these ranges (Table 6 ).

Table 6. Averaged circle diameter.

\begin{tabular}{|c|c|c|c|c|c|}
\hline DIAMETER (m) & $\begin{array}{l}\text { RINGS } \\
\text { small }\end{array}$ & $\begin{array}{l}\text { AT MULTI-CIRCLE } \\
\text { large unspe }\end{array}$ & $\begin{array}{l}\text { SITES } \\
\text { ecified }\end{array}$ & $\begin{array}{l}\text { RINGS AT SINGLE } \\
\text { CIRCLE SITES }\end{array}$ & TOTAL \\
\hline $10.0-12.0$ & 1 & 0 & 0 & 1 & 2 \\
\hline $12.1-14.0$ & 2 & 0 & 0 & 0 & 2 \\
\hline $14.1-16.0$ & 2 & 0 & 1 & 2 & 5 \\
\hline $16.1-18.0$ & 0 & 0 & 0 & 3 & 3 \\
\hline $18.1-20.0$ & 0 & 1 & 1 & 1 & 3 \\
\hline $20.1-22.0$ & 0 & 1 & 2 & 2 & 5 \\
\hline $22.1-24.0$ & 0 & 1 & 0 & 1 & 2 \\
\hline $24.1-26.0$ & 0 & 5 & 0 & 1 & 6 \\
\hline $26.1-28.0$ & 0 & 0 & 0 & 0 & 0 \\
\hline $28.1-30.0$ & 0 & 3 & 0 & 0 & 3 \\
\hline Total: & 5 & 11 & 4 & 11 & 31. \\
\hline
\end{tabular}

It is tempting to regard the smaller single rings as the remaining small circles of multiple circle sites and the larger single rings as either the surviving large circles of multiple circle sites or true single ring sites. However, the historical literature does not support this interpretation. As mentioned earlier, Aldridge's account of single ring, Dora initiation sites indicates that the circles used varied from 5.5 to $23.0 \mathrm{~m}$ in diameter, a range spanning those of both the known small and the known large circles in the sample. Moreover, the descriptions of Fraser, Mathews and Petrie all suggest circles with an equal or greater range of sizes (see also steele 1984:28). It seems then, that isolated circles cannot be assigned to either double or single circle site categories using size alone as a criterion.

Shape is another important site attribute. This was assessed in terms of an "index of elongation", the ratio of the length of a circle's short axis to the length of its long axis. This index is consequently a measure of the extent to which a site deviates from true circular shape. The 
results for the sites in the sample for which this information is available are presented in Table 7, where the indices are grouped in intervals of 0.05 . Known small circles exhibit indices ranging between 0.75 and 0.87 and known large circles between 0.72 and 0.93 . There are, however, only three examples of small circles in the sample and this is too few to permit any definite conclusioris,

Table 7. Degree of circle eiongation $(1.00=$ perfect circle).

\begin{tabular}{|c|c|c|c|c|c|}
\hline $\begin{array}{l}\text { INDEX OF } \\
\text { ELONGATION }\end{array}$ & $\begin{array}{l}\text { RINGS } \\
\text { small }\end{array}$ & $\begin{array}{l}\text { AT MULTI-CIRCLE } \\
\text { large unspe }\end{array}$ & $\begin{array}{l}\text { SITES } \\
\text { ecified }\end{array}$ & $\begin{array}{l}\text { RINGS AT SINGLE } \\
\text { CIRCLE SITES }\end{array}$ & TOTAL \\
\hline $0.71-0.75$ & 1 & 1 & 0 & 1 & 3 \\
\hline $0.76-0.80$ & 1 & 0 & 0 & 1 & 2 \\
\hline $0.81-0.85$ & 0 & 2 & 1 & 0 & 3 \\
\hline $0.86-0.90$ & 1 & 4 & 3 & 3 & 11 \\
\hline $0.91-0.95$ & 0 & 3 & 0 & 4 & 7 \\
\hline $0.96-1.00$ & 0 & 0 & 0 & 3 & 3 \\
\hline \multirow{2}{*}{ Total: } & ---- & --------------- & --ー-ー-ー & ----------------1 & ----- \\
\hline & 3 & 10 & 4 & 12 & 29 \\
\hline
\end{tabular}

An observation of particular interest is that while in the case of averaged diameter the results for single ring and multiple ring sites overlap, in the case of circle elongation there is an evident difference between them: the ranges differ, the respective frequency distributions peak at different points, and only circles associated with single ring sites exhibit true circular shape. Were it possible to test a larger sample, differences in shape might provide a basis on which to distinguish between isolated rings representing what were originally single circle, Dora- or Kaiabara-type sites and rings representing the surviving circles of multiple ring sites.

A final point regarding circle shape concerns the triple-ring site at Tamborine. The two preserved circles of this site have averaged diameters of 13.3 and $28.4 \mathrm{~m}$ and each exhibits an index of elongation of 0.88 , thus conforming to other circles in the sample. The third ring was quite different in morphology, however. Given the figures provided by shirley (1911:104), it would have displayed an index of elongation of 0.38 , well out of the range of any other known circle in the region. This supports the previously mentioned local tradition that the third ring of the site was used for a purpose other than initiation. It also indicates that most, if not all, of the one and two ring sites in the region cannot be regarded as partially preserved three ring siteg-for them to be so, the uniquely shaped third ring would have had to perish in every case, a very unlikely prospect.

Site orientation. Two site attributes relate to orientation. These are the alignment of the major axis of a circle, if it has one, and the direction the pathway leaves the circle, again if one is present. The the available information on orientation of major axes is summarized in Table 8. As the table shows, only one of the sites in the sample, one of the four known small circles, is aligned in an east-west orientation. Taking the figures overall, there is a strong preference for major axes to align 
in N-S or NW-SE directions. This tendency is especially pronounced in the case of known large circles, where 10 of the 11 examples are orientated in this way.

Table 8. Orientation of major circle axis.

\begin{tabular}{lccccc}
\hline DIRECTION & \multicolumn{2}{c}{ RINGS } & AT & MULTI-CIRCLE SITES & RINGS AT SINGLE \\
& Small & large & unspecified & CIRCLE SITES & TOTAL \\
\hline N-S & 0 & 3 & 3 & 1 & 7 \\
E-W & 1 & 0 & 0 & 0 & 1 \\
NE-SW & 1 & 1 & 0 & 2 & 4 \\
NW-SE & 2 & 7 & 1 & 1 & 1 \\
NNW-SSE & 0 & 0 & 0 & 1 & 1 \\
WNW-ESE & 0 & 0 & 0 & 8 & 27 \\
Total: & 4 & 11 & 4 & & \\
\hline
\end{tabular}

Pathway direction is indicated by the bearing at which a path leaves a circle. The available information on this is presented in Table 9, where directional bearings are grouped into four categories. In order to consider this attribute from a consistent perspective, only the large circles of a pair and sites of apparent single circle morphology are included. As indicated in the table, pathways depart from their circles at a bearing between $135^{\circ} \mathrm{SE}$ and $224^{\circ} \mathrm{sw}$ in over two thirds of the sites in the sample. A further point of interest regarding this sample of sites is that the point of pathway departure and the alignment of a circle's major axis do not always coincide. Of the 14 sites displaying a major axis of orientation, and for which there is sufficient data, 1 I have paths that leave the circle at an angle within $45^{\circ}$ of either side of the major axis, but 3 have paths that leave at an angle greater than $45^{\circ}$. In some of the latter, the bearing at which the path departs the circle approaches a $r i g h t$ angle to the circle's main alignment.

Table 9. Direction at which pathway departs circle.

\begin{tabular}{rcr}
\hline QUADRANT & $\begin{array}{c}\text { NUMBER OF SITES } \\
(n=22)\end{array}$ & PERCENTAGE OF SITES \\
\hline $45^{\circ}$ NE - $134^{\circ}$ SE & 2 & 9.18 \\
$135^{\circ}$ SE $-224^{\circ}$ SW & 15 & 68.28 \\
$225^{\circ}$ SW $-314^{\circ}$ NW & 3 & 13.68 \\
$315^{\circ}$ NW $-44^{\circ}$ NE & 2 & 9.18 \\
\hline
\end{tabular}

Distribution of morphological types. It was suggested in an earlier section that differences in morphology may result from differences in function, differences in ritual tradition, or differences in age. All of these factors, singly or in combination, have implications for site distribution and spatial relationships. 
There do appear to be significant intra-regional differences in the gross morphologies of earth circlesites. For instance, some $55 \%$ of the sites in the northern part of the region (the area east of Mt stanley and north of a line from Moore to Toorbul point) are single ring sites, while only $10 \%$ are of the classic "2 rings + path" type (Figure 3 and Table 10 ). This contrastg markedly with the central portion of the region (south of the Moore-Toorbul 1 ine and from the Brisbane Valley to the coast), where 198 of sites are of the single ring type, but over 758 consist of two rings and a pathway. The south coast and adjacent interior (the area south of Wellington point and east of Teviot Brook) display the greatest diversity of morphologies--this area not only includes single and double ring sites, but also a triple ring site, a site one of whose circles was made of stones, and a site consisting of a ring within a ring. Lastly, the western part of the region exhibits the greatest homogeneity in site morphology; although there are only five reliably located sites in this area, four of them are of the "1 ring + path" type, and these represent two thirds of such sites known in the Moreton Region.

Table 10. Subregional distribution of gross morphologies.

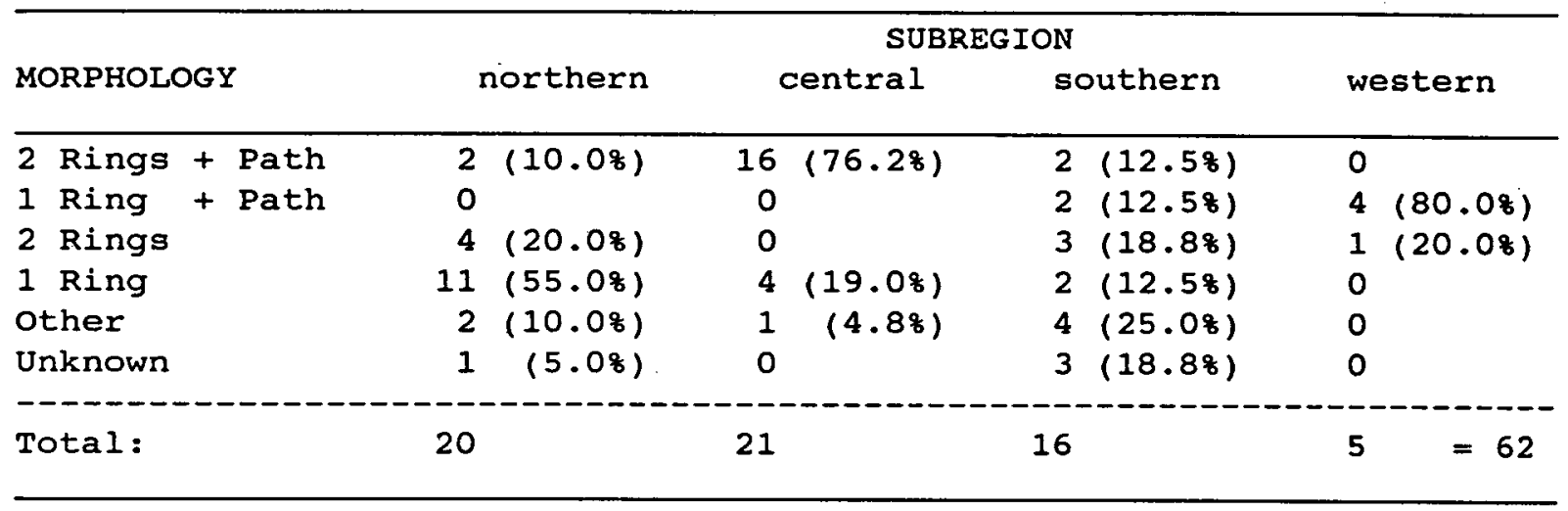

There are several possible reasons for this pattern of subregional variation. The most obvious conjecture is that the differences reflect different "styles" of ceremonial site construction associated with different ritual traditions and, by implication, different social groupings. The preponderance of single circle sites in the north, for example, suggests affinities with the Dora and Kaiabara ritual practices Aldridge and Howitt attribute to areas north and northwest of the Moreton Region, while the high proportion of "2 rings + path" and " 1 ring + path" sites in, respectively, the central and western parts of the region suggests that yet other ritual traditions prevailed in these districts. The morphological heterogeneity apparent in the southern part of the region might be a manifestation of a more complex social and religious situation, one stemming from participation in a ritual network extending, on the one hand, into the northern coast and northern riverg regions of New south wales and, on the other, across the dividing Range and into the Darling Downs. A particularly interesting feature of the way in which site morphologies seem to cluster into subregions is that these subregional clusters are usually bounded by major landscape features--rivers and ranges especially. 


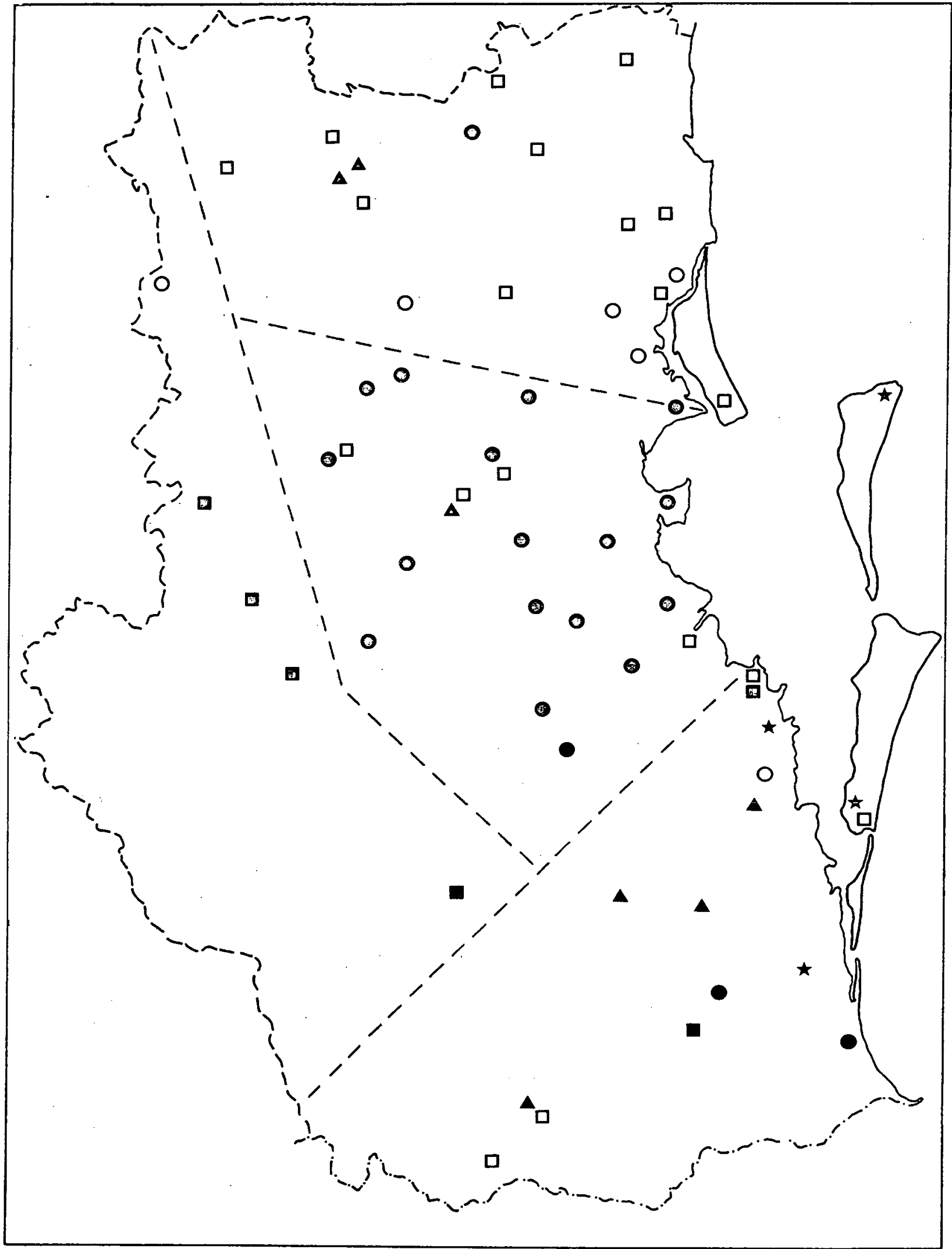

Figure 3. Subregional distribution of gross morphologies (stars = unknown/equivocal morphology; solid circles $=$ " 2 rings + Path": hollow circles = "2 rings"; solid squares = "1 ring" + Path; hollow squares = "1 ring"; triangles = other morphologies). 
These interpretations cannot be accepted without reservation, however. As stressed earlier, attempts both to perceive pattern and to explain it are made all the more difficult by the problems of differential site preservation and selective degradation of site components. Consequently, Figure 3 and Table 10 may not accurately reflect the original distribution of morphological variation in the region, although they do tend to corroborate the distribution reconstructed from historical accounts (Figure 2).

A different approach is to focus on certain morphological details of extant sites rather than on reported gross morphology alone. This approach is instanced in Table 11 in the form of a breakdown of earth circle morphologies in terms of ring elongation and pathway orientation among the 26 sites for which this information is available. For the purposes of this analysis the number of circles present were disregarded, this because a double ring site is readily transformed into a single ring site with the disappearance or destruction of one of its circles. Pathway orientation was included, however. Although pathways are vulnerable to destruction, even if they are absent their former presence and alignment can usually be ascertained from gaps in the perimeter mounds of surviving circles.

Table 11. Breakdown of site morphologies on the basis of circle shape and pathway orientation.

26 Sites for which data are available

4 Sites for which pathway existence is indeterminate

1 site for which there is no physical evidence of a pathway

3 sites disturbed

22 Sites for which there is some evidence of a pathway

3 sites of circular shape, all with pathways departing from the SE-SW quadrant of the circle

19 Sites of elongated shape

4 Sites for which the pathway leaves the circle at an angle greater than $45^{\circ}$ to the circle's major axis

1 site with pathway departing from the $\mathrm{sW}-\mathrm{NW}$ quadrant of the circle

3 sites with pathways departing from the SE-SW quadrant of the circle

15 Sites for which the pathway leaves the circle at an angle within $45^{\circ}$ of either side of the major axis

2 sites with pathways departing from the NE-SE quadrant of the circle

2 sites with pathways departing from the $\mathrm{NW}-\mathrm{NE}$ quadrant of the circle

2 sites with pathways departing from the SW-NW quadrant of the circle

9 sites with pathways departing from the SE-SW quadrant of the circle

An important observation that emerges from consideration of Table 11 is that 22 sites, 858 of the sample, exhibit some evidence of a pathway. This sample contains over 608 of the extant sites in the Moreton Region and thus can be taken as representative of them. Given this, it is highly unlikely 
that many sites in the region lacked pathways--most sites consisted of either one or two circles and a path. In the case of single circle sites, a secluded clearing in dense vegetation or some other setting offering comparable security probably served as the functional and ritual equivalent of a second circle, as Aldridge (in Howitt 1904) indicates. In any event, these results affect the interpretation of Figure 3 and Table 10; the northern part of the region, for example, contains not just two sites with a path, but seven sites with paths, three of which are double circle sites.

The breakdown in Table 11 can also be considered from a spatial perspective. On the basis of similarities and differences in shape, location of pathway exit and relation of pathway to circle axis, two subpopulations can be identified among the sites in the sample. subpopulation 1 consists of contiguous or semi-contiguous sites that exhibit (a) some evidence of a pathway, (b) elongated shape, (c) a pathway that departs from the SE to NW quadrant of the circle, and (d) a pathway that leaves the circle at an angle $\pm 45^{\circ}$ to the major axis. sites in Subpopulation 2 exhibit the same first three traits, but differ in that the pathway departs the circle at an angle $>45^{\circ}$ to the major axis. Although the vagaries of site preservation no doubt impinge on the result, it is interesting that these subpopulations do not occupy areas so much as "transects" of the region and that these transects align in a generally NWSE direction (Figure 4). This orientation parallels the most common alignment of site axes, as well as the trend of the region's major geological structural units (Department of Mines 1980).

These observations have significant implications. One is that in extending from coast to interior and from lowlands to highlands, the transects cross-cut the major physiographic and ecological zones within the region, a feature that would have offered considerable flexibility in the selection of environmental settings in which to hold ceremonial gatherings. A second, and no doubt related, characteristic of the transects is that they appear to have extended across the various areas from which people were drawn to participate in initiation ceremonies (see sullivan 1977:35). As a result, not only would these linear arrangements of morphologically related sites have linked locales of contrasting ecology, but also differing geographically based social or ritual units.

Possibly this particular orientation of site axes and site transects deriver from spatial relationships encoded in myth, in which case earth circles tangibly manifest important directional aspects of Aboriginal mythology. If this is true, then site orientation and the placement of sites relative to one another would have served to express dominant themes in local belief systems and, in common with ground sculptures and carved trees, could have functioned in initiations as components of a complex set of associated instructional symbols. Here it is interesting that linear distribution of morphologically related sites is reminiscent of the linear dreaming tracks that are such a conspicuous feature of the Aboriginal mythological landscape. At any rate, earth circles undoubtedly represent more than merely physical settings for ritual activity, and this was almost certainly incorporated into their architecture and location. 


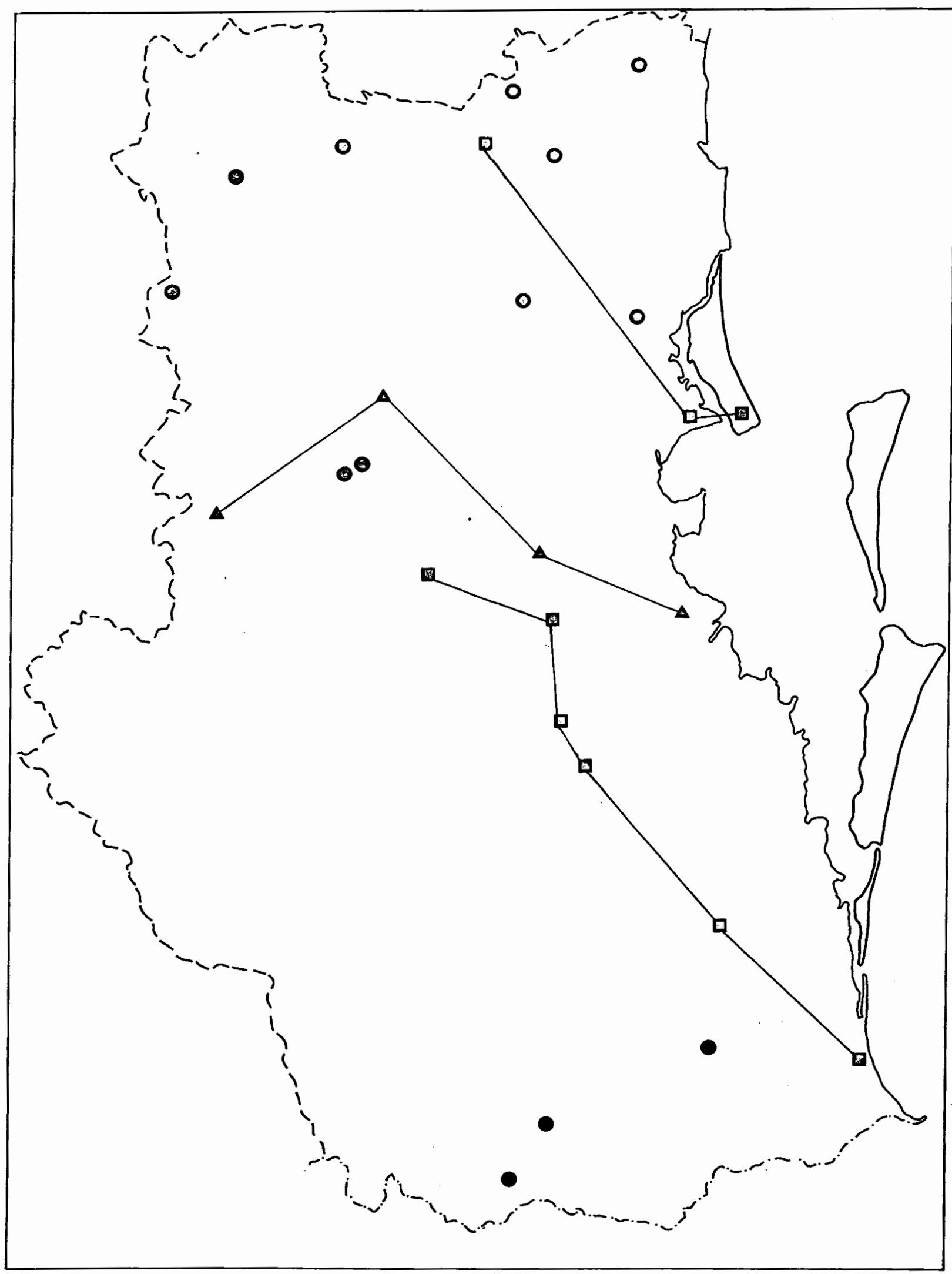

Figure 4. Distribution of sites subjected to detailed morphological analysis (squares $=$ Subpopulation 1; triangles $=$ subpopulation 2). 
This examination of site morphologies and their distributional implications has a bearing on one other matter concerning site location. It was noted in the preceding section that there seems to be a kind of competition among sites. This observation emerged from an apparent tendency toward regular distribution among the sites in the population. Contrary to the general trend, however, there are some sites that are located in relatively close proximity to one another. In their case, insight is gained not from the distances separating them, but from the lack of it.

In Table 12 are listed the number of nearest-neighbour pairs, the two sites of which exhibit either the same or different types of gross morphology. Neither island sites nor sites of unknown morphology are included, and nearest-neighbour pairs are not duplicated in the tabulation. There are two gignificant features of the data summarized in the table. The firgt is the high proportion of nearest-neighbour sites six or more kilometres apart that share the same morphologies. This is greater than would be expected from chance alone: Given the frequencies presented in Table 4, random distribution of morphologies among nearest neighbours would be expected to result in them having the same morphology in about $25 \%$ of cases. The actual frequency with which similar morphologies occur among these nearest neighbours is over twice this figure. This reflects the tendency noted earlier for sites of similar gross morphology to cluster subregionally.

Table 12. Morphological similarity and difference among nearestneighbour sites.

\begin{tabular}{lcc}
\hline DISTANCE BETWEEN & MORPHOLOGIES OF NEAREST NEIGHBOURS \\
NEAREST NEIGHBOURS & same & different
\end{tabular}

\begin{tabular}{rll}
\hline $0-5 \mathrm{~km}$ & $1(14.38)$ & $6(85.78)$ \\
$6-10 \mathrm{~km}$ & $4(50.08)$ & $4(50.08)$ \\
$11-15 \mathrm{~km}$ & $8(53.38)$ & $7(46.78)$ \\
$16-20 \mathrm{~km}$ & $2(50.08)$ & $2(50.08)$ \\
$>20 \mathrm{~km}$ & $2(50.08)$ & $2(50.08)$
\end{tabular}

But an equally important feature of Table 12 is the result for nearest neighbours separated by a distance of $5 \mathrm{~km}$ or less. This result is highlighted in Table 13. The obvious point illustrated here is that, with one exception, these nearest neighbours are not morphologically similar. This indicates that there is a certain critical distance beyond which nearest neighbours are no longer in "competition" with one another. At less than this critical distance, however, a kind of morphological "competitive exclusion principle" seems to operate to disallow spatial association of sites of the same type.

There are several possible explanations for the appearance of disparate morphologies among the sites in Table 13. Following the earlier suggestion, one is that the sites of each pair represent the products of different ritual traditions. This seems unlikely, however, given the relatively short distances involved and the fact that most of the morphologies occurring among these sites also appear among other sites at several widely separated localities in the region. Possible exceptions are 
KA:A12 and KA:A13, the sites at Rathdowney. These two "sites" are almost certainly parts of the same single ceremonial site. Although probably once similar to other sites in consisting of two circular components joined by a path, one of the former had a distinctive configuaration, a ring within a ring. This is the only circle of its kind in the region and certain of its features recal 1 the kind of initiation site Hall (1907) reports for the Killarney district to the west.

Table 13. Morphologies of nearest-neighbour sites $\leq 5 \mathrm{~km}$ apart.

\begin{tabular}{lcc}
\hline NEAREST NEIGHBOURS & DISTANCE \\
APART $(\mathrm{km})$ & MORPHOLOGIES
\end{tabular}

\begin{tabular}{lll}
\hline $\mathrm{KA}: \mathrm{A} 12$ / KA:A13 & 1 & 1 Ring / 1 Ring within a Ring \\
$\mathrm{LB}: \mathrm{A} 10 / \mathrm{LB}: \mathrm{A} 42$ & 2 & 1 Ring + Path / 1 Ring \\
$\mathrm{KB}: \mathrm{A} 53 / \mathrm{KB}: \mathrm{A}(\mathrm{d})$ & 3 & 2 Rings + Path / 1 Ring \\
$\mathrm{KC}: \mathrm{A} 51 / \mathrm{KC}: \mathrm{A} 64$ & 3 & Both Bare Earth Circles \\
$\mathrm{KB}: \mathrm{A}(\mathrm{b}) ; \mathrm{KB}: \mathrm{A}(\mathrm{C})$ & 4 & 2 Rings + Path / 1 Ring \\
$\mathrm{KB}: \mathrm{A} 62 / \mathrm{KB}: \mathrm{A} 62 \mathrm{a}$ & 4 & 2 Rings / 1 Ring \\
$\mathrm{KC}: \mathrm{A} 20 /$ Coochin Creek & 5 & 4 Ring
\end{tabular}

A second possibility is that the differing morphologies reflect differing functions. Perhaps one of the closely placed sites was used for initiation and the other for fights, as seems to have been the case at Nimbin, or maybe one was used by men and the other by women. At any rate, the possibility of functional distinctiveness seems most applicable to the anomalous morphologies among these sites--the "flat, smooth" and "bare earth" circles. The latter, especially, conflict with the usual earth circle morphological pattern (if, indeed, these peculiar sites are even of Aboriginal origin) and their occurrence in the vicinity of one another may not have the implications that it does for conventional site types.

Nevertheless, if the more common one and two ring sites had separate but consistently associated uses, such as fighting and initiation, they would be expected to occur in close spatial association much more frequently than they do. Here it is of special interest that four cases out of the seven listed in Table 13 involve the pairing of sites consisting of one or two rings and a path with sites consigting of one ring only (also, an as yet unlocated single ring site is reported to have existed about $1 \mathrm{~km}$ away from the "2 rings + path" site at Samford [Marks 1970]). This may be an instance of the third posgibility-temporal differences. Assuming that European activities have not altered the process, the single ring sites may represent the persisting remains of older sites, while the double and single ring sites with paths represent their more recently constructed, hence better preserved, replacements. This would account for both the differences in morphology and their spatial proximity. If true, this possibility also provides the only available non-destructive means of arriving at some idea of the relative ages of these sites.

\section{Environmental Determinants of site Location}

Several environmental factors were posited to have had a major influence on the selection of earth circle locations. These include 
availability of food and water, workable soil and suitable topography, each of which is considered in the following.

Water. An adequate water supply takes precedence as a necessary resource in the vicinity of earth circle sites. Water has long been recognized as fundamental to campsite location (e.g., Peterson 1973:184; Jochim 1976:61), and the water requirements of large numbers of people gathered for ceremonial activity would have far exceeded those of the more usual huntergatherer production or residential units. In addition, water may have been required for pigment preparation and construction of ground sculptures, as well as for other ritual uses. Because water is not readily transported, earth circle sites can be expected to occur close to reliable supplies.

Using 1:50,000 series topographic maps or their equivalent, the linear distance from each site in the study population to nearest water was measured. Ag Table 14 indicates, 48 of sites are situated within $0.2 \mathrm{~km}$ of a water source of some kind and $85 \%$ are within $0.6 \mathrm{~km}$. Moreover, for 618 of the sites in the population the nearest source. of water is perennial and for 398 it is intermittent.

Table 14. Distance to and type of nearest source of freshwater.

\begin{tabular}{|c|c|c|c|c|c|c|}
\hline \multicolumn{3}{|c|}{ DISTANCE $(\mathrm{km})$} & \multirow{2}{*}{\multicolumn{2}{|c|}{$\begin{array}{l}\text { NUMBER OF SITES } \\
(N=62)\end{array}$}} & \multirow[t]{2}{*}{ PERCENTAGE OF } & \multirow[t]{2}{*}{ SITES } \\
\hline AND 2 & TYPE & OF WATER & & & & \\
\hline 0 & -0 & .20 & & 30 & 48.48 & \\
\hline 0.21 & -0 & .40 & & 16 & 25.88 & \\
\hline 0.41 & -0 & .60 & & 7 & 11.38 & \\
\hline 0.61 & -0 & .80 & & 2 & 3.28 & \\
\hline 0.81 & -1 & .00 & & 3 & 4.88 & \\
\hline 1.01 & -1 & .20 & - & 0 & - & \\
\hline 1.21 & -1 & .40 & & 2 & 3.28 & \\
\hline 1.41 & -1 & .60 & & 0 & - & \\
\hline 1.61 & -1 & .80 & & 0 & - & \\
\hline 1.81 & -2 & .00 & & 1 & 1.68 & t \\
\hline 2.01 & -2 & $.20^{\circ}$ & & 1 & 1.68 & \\
\hline close & est & freshwàter & perennial & 38 & 61.38 & \\
\hline Close & est & freshwater i & intermittent & 24 & 38.78 & \\
\hline Close & est & water $=1 \mathrm{st}$ & order stream & 8 & 12.98 & \\
\hline & & $2 n d$ & order stream & 7 & 11.38 & \\
\hline & & $3 r d$ & order stream & 6 & $9.7 \%$ & \\
\hline & & 4 th & order stream & 3 & $4.8 \%$ & \\
\hline
\end{tabular}

Intermittent streams can be classified in terms of stream order, a ranking of streams according to number of tributaries. streams with no tributaries are first order streams. The joining of two first order streams creates a second order stream, the joining of two second order streams results in a third order stream, and so on (Van Riper 1971:439). Although stream order is not a direct measure of discharge volume, the implication is that in any given catchment higher order streams provide greater quantities and more reliable supplies of water than do lower order streams. Consequently, one would anticipate that where the source of water 
nearest a site is an intermittent watercourse, it will be a higher order stream. This is not the case, however. Sites are distributed in almost equal proportions near first, second, and third order streams, while the closest supply of water is a forth order stream for the least number of sites (Table 14).

Turning to nearest perennial water supply, 538 of the sites in the study population are within $0.5 \mathrm{~km}$ of permanent water, 748 are within 1.0 $\mathrm{km}$ and all but one of the remainder are located between 1.0 and $5.5 \mathrm{~km}$ from a water supply of this kind (Table 15). Altogether, 898 of sites are within $2.0 \mathrm{~km}$ of permanent water. One site, that at Hilliard's Creek (LB:A10), is apparently more than $10 \mathrm{~km}$ from perennial water, but this anomaly may be due to the relevant maps not showing all the perennial water sources in the area.

Table 15. Distance to nearest perennial water supply.

NUMBER OF SITES

$(\mathrm{N}=62)$

\begin{tabular}{rrc}
\hline $0-0.50$ & 33 & 53.28 \\
$0.51-1.00$ & 13 & 21.08 \\
$1.01-1.50$ & 4 & 6.58 \\
$1.51-2.00$ & 5 & 8.18 \\
$2.01-2.50$ & 0 & - \\
$2.51-3.00$ & 3 & 4.88 \\
$3.01-3.50$ & 0 & - \\
$3.51-4.00$ & 2 & -28 \\
$4.01-4.50$ & 0 & - \\
$4.51-5.00$ & 0 & 1.68 \\
$5.01-5.50$ & 1 & - \\
$5.51-6.00$ & 0 & 1.68 \\
\hline
\end{tabular}

These findings were checked against the sites selected for field examination. Of the 22 sites in the field assessment sample, 19 (868) were found to be no more than $2.0 \mathrm{~km}$ away from an obvious supply of perennial, potable water. The exceptions are sites KC:A71, LA:A7 and Gibson Island, the latter two of which may have been located near now drained or filled swamps. These field observations accord with those obtained from map analysis of the study population as a whole, as well as with those historical accounts suggesting that water was an important locational factor. Furthermore, it should be stressed that these results are likely to be conservative. Deforestation, construction of dams and canals, an increase in impervious surfaces, and lowering of the water table have all significantly altered the region's drainage systems, especially by causing previously perennial streams to become intermittent (strahler and strahler 1973: 336; Van Ripper 1971:180-181).

Topography. Maps of the same scale were used to analyze the topographic settings of sites. Historical accounts indicate that a basic function of topography was to provide a visual barrier between the larger, public ring and the smalier ring or clearing, where the more secret aspects of the ceremony transpired. This was often achieved by constructing sites on the sides or ends of ridges, so that a rise obscured the view of one ring from the other. 
Ridges possess characteristics that render them especially desirable locations for ceremonial activity. Ridges provide security and seclusion in that they constitute naturally defined areas that can be set aside for restricted entry-access is easy to monitor and regulate. In addition, earth circles atop ridges are less likely to be visible from the surrounding country than are sites on lower land overlooked by high ground. Ridges may also have been used as a means of separating earth circle sites from their associated campsites. Circles constructed parallel to, but below the crest of a ridge, would have been sufficiently removed from a campsite located on the other side of the ridge to maintain secrecy.

Ridges may also have been invested with special meaning in local belief systems. Ceremonies conducted at these elevated and commanding locations may have been perceived as physically and symbolically separate from the secular and mundane aspects of the participants' lives, thus intensifying the experience and significance of ritual activity.

As discussed earlier, nearly 908 of the earth circle locations in the study population are situated at or below an altitude of $150 \mathrm{~m}$. Although this might be indicative of general topographic trends in site placement, more detailed evaluation on the basis of Archaeology Branch records and the information on contour maps revealed specific topographic preferences in site location, regardless of altitude. Of the 62 sites in the population, 638 are on or associated with ridges (i.e., on the top, side or toe of a ridge), 35\% are on apparently 'flat' ground and 28 are in areas of dune and swale. Beçause analysis was based on $20 \mathrm{~m}$ contour intervals, it is possible that the number of sites on level terrain is exaggerated--some of these sites may actually occur on ridges less than $20 \mathrm{~m}$ in height. Field examination indicated, for instance, that the Rathdowney sites (KA:A12, $\mathrm{KA}: \mathrm{Al3}$ ) are on elevated ground, even though this is not apparent on maps.

The picture of site placement derived from map analysis was confirmed by the field study. Of the 22 locations in the field assessment sample, 688 are on ridges and 328 on flat land. It is interesting that in 4 cases the pathways connecting component rings are not situated on ridge crests, but slightly to one side, probably to shield them from view. Similarly, the sites at Lowood (Bornong Project No. 33) and Purga Creek (KB:A80) are situated parallel to, but below the crests of, ridges. In each case, there is evidence of a campsite located on the opposite side of the ridge and not more than $600 \mathrm{~m}$ away.

Ironically, the overriding importance of security and seclusion is best exemplified by sites that do not conform to the general trend of association with ridges. For ingtance, the lesser ring of the Nerang aite (Robinson 1952), is located not on a ridge but in thick gallery vine-forest on an alluvial flat. Likewise, dense rainforest scrub would have secluded the smaller ring of the Oakey Creek site (KB:A81) (Archaeology Branch records; Queensland Electricity Generating Board 1980:8). These exceptions emphasize that security took precedence over the importance of merely siting earth circles on ridges. It seems that security was of primary importance and that placement on ridges was a means to this end, but not the only one.

Soil. Soil type was expected to have a bearing on site location for geveral reasons. Historical accounts suggest that unstructured and easily dug soils were favoured for site construction. These soils would also have assisted site curation, making it easier as for only a few men to repair a 
site before periods of use, as Mathews (1910:105) indicates was done. A final possibility is that easily dug soils suited the abilities of older men, the ones who possessed the esoteric knowledge required for the construction of sites to prescribed ritual specifications.

To test the proposition that soil type influenced site location, 60 of the sites in the population were plotted on a soils map of the Moreton Region (Co-ordinator General 1972). Because details were unavailable for the two remaining sites in the population, they were excluded from the analysis. Of the site locations considered, $53 \%$ occur on unstructured soils ( $32 \%$ on sands and 218 on loams) and 478 on soils of a variety of other types.

This is not as strong an association betweeñ 8 ite location and unstructured soils as was anticipated. In this case, however, there is a marked difference between the results obtained from map analysis and those obtained from fieldwork. Except for Gibson Island (now a fertilizer plant), soil samples were collected at each of the locations selected for field investigation. These samples were washed in a 200 sieve, thus retaining all particles larger than $0.86 \mathrm{~mm}$. The percentage of sand was then calculated by weight. The soil at 17 (818) of the 21 sites sampled was found to have a sand content of 708 or more. Such soils are 'sand' by definition (Basile 1973:34).

The discrepancy between map and fieldwork results is undoubtedly due to the presence of unmapped pockets of unstructured soils. The proportion of sites in the total population located on unstructured soils likely approaches that of sites in the fieldwork sample.

Geological Boundaries. The relevance of this factor to environmental heterogeneity and food resource availability was argued in the summary of research methods. Proximity to geological boundaries was determined by plotting the sites in the population on the "Moreton Geology" map compiled by the Department of Mines (1980). The results are presented in Table 16: 718 of sites are no further than $0.5 \mathrm{~km}$ from a geological boundary and 798 are within $1.0 \mathrm{~km}$. Assuming that geological boundaries are indeed indicators of ecological diversity, this diversity was readily accessible to a major proportion of the sites in the population.

Table 16. Distance to nearest geological boundary.

\begin{tabular}{lcc}
\hline DISTANCE $(\mathrm{km})$ & NUMBER OF SITES & PERCENTAGE OF SITES \\
& $(N=62)$ &
\end{tabular}

\begin{tabular}{rrr}
\hline $0-0.25$ & 26 & 41.98 \\
$0.26-0.50$ & 18 & 29.08 \\
$0.51-0.75$ & 1 & 1.68 \\
$0.76-1.00$ & 4 & 6.58 \\
$1.01-1.25$ & 0 & - \\
$1.26-1.50$ & 2 & 3.28 \\
$1.51-1.75$ & 3 & 4.88 \\
$1.76-2.00$ & 2 & 3.28 \\
$>2.00$ & 6 & 9.78
\end{tabular}


Field observations support this conclusion. Although the dominant vegetation type in the immediate vicinity of almost all the sites in the sample is open eucalypt forest, in most cases this is accompanied by areas

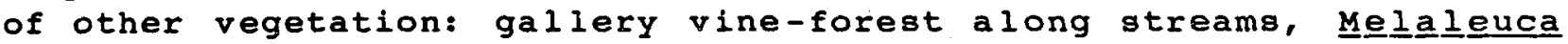
communities in low-lying, poorly drained localities and closed forest on south-facing slopes and in deep gullies. European modifications notwithstanding, a range of distinct biotic communities are well within range of each of the locations examined.

This finding is further reinforced by the earlier observation that the greater proportion of sites occur at or below $150 \mathrm{~m}$ in altitude. A wide range of environmental zones (estuarine, marine, montane, riverine and swampland) are readily accessible in those parts of the region below this elevation (Draper 1980; Hall 1982).

Comparison with Control Population. Food and water supplies, topography and soil type appear to have been important factors in the siting of earth circles. It is possible, however, that these relationships merely reflect the nature of the Moreton environment-that water, ridges, unstructured soils and geological boundaries are so common in the region that any randomly selected set of points would invariably exhibit the same environmental associations as do earth circle sites.

To test this possibility, a control population of 62 site locations was created and mapped by means of randomly selected grid reference points. since four of the sites in the actual population are located on Moreton Bay islands, the control population was stratified into mainland and island divisions, with four randomly selected locations allotted to the latter (Figure 5). This phantom population was subjected to the same analysis applied to the actual population.

The results of this analysis, along with comparable data for the actual population, are presented in Table 17. The contrast between actual and control populations is readily apparent. For instance, although almost all locations in the control population occur within $0.6 \mathrm{~km}$ of a water supply of some kind (a reflection of the well watered nature of the Moreton Region), actual sites for which the closest source of water is perennial outnumber similarly placed control locations by nearly two to one. This emphasizes the importance of selecting locations where resources were assured, not merely potential. Certainty of resource availability would have been a necessary concomitant of scheduling the attendance of large groups of people at a ceremony well in advance of the event.

Equally gignificant differences apply with regard to soil type--even though the proportion of actual sites located on unstructured soils is probably understated-and topography. A notable feature of the latter is the range of topographic settings in which the randomly placed locations occur. This is in marked contrast to actual sites, where there is a decided bias in favour of ridges. Also of interest is the proportion of control locations (558) occurring below $150 \mathrm{~m}$ in altitude. This figure is significant because it approximates the proportion of land below this elevation in the Moreton Region. In this case at least, and in contrast to actual site locations, control locations mirror the character of the region's environment.

overall, these results indicate that the locational associations exhibited by the sites in the actual population are not an inevitable 
product of the character of the Moreton Region and reinforce the conclusion that the distribution of sites relative to environment is not fortuitous, but a reflection of selective site placement.

Table 17. Comparison of actual and control populations.

\begin{tabular}{lcc}
\hline ENVIRONMENTAL & ACTUAL & CONTROL \\
VARIABLE & POPULATION & POPULATION
\end{tabular}

\section{Water}

Within $0: 6 \mathrm{~km}$ of water source of any kind closest water is intermittant closest water is perennial

Perennial water within $1.0 \mathrm{~km}$

Perennial water within $2.0 \mathrm{~km}$

$\begin{array}{ll}858 & 948 \\ 398 & 638 \\ 618 & 378 \\ 748 & 528 \\ 898(868) & 698\end{array}$

Topography

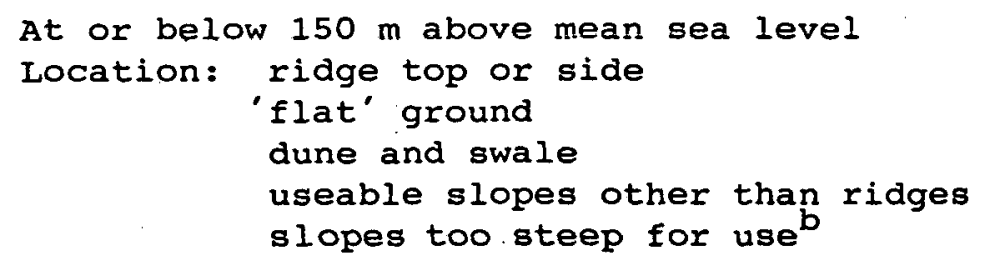

$\begin{array}{rrr}878 & & 558 \\ 638 & (688) & 318 \\ 358(328) & 348 \\ 28 & & 28 \\ 08 & 218 \\ 08 & & 138\end{array}$

Soil Type

Unstructured

structured

$538(818)$

268

478

748

Geological Boundaries

Nearest boundary within $0.5 \mathrm{~km} \quad 718 \quad 538$

Nearest boundary within $1.0 \mathrm{~km} \quad 798 \quad 698$

aigures in parentheses refer to the field study sample.

$b$ Qualitative assessment based on closeness of $20 \mathrm{~m}$ contour lines.

\section{CONCLUSIONS}

The major aim of this investigation was to identify and explain the preferences for earth circle locations in the Moreton Region. The results are usefully summarized in terms of a site location model predicated on a hierarchy of locational criteria, each level of which narrows the options for site location. It should be stressed that this model is inferred from the surviving record of site locations and, while possibly in accord with the emic reality of Aboriginal decision-making, its principal purpose is to serve as a heuristic predictor of earth circle locations. In addition, several problems regarding earth circles and their distribution require further investigation, and for this reason the discussion concludes with some suggestions for future research. 


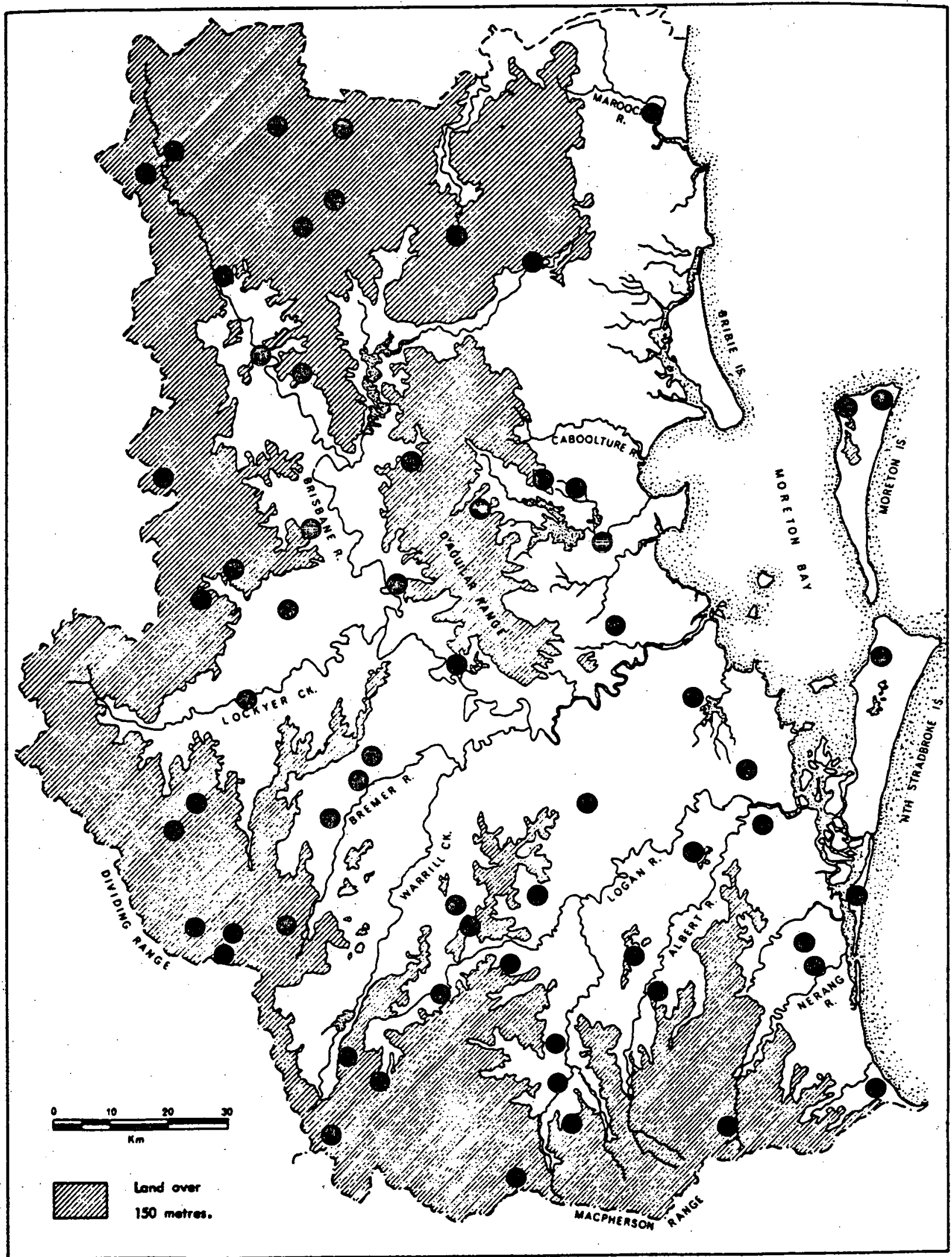

Figure 5. Distributions of points in control population. 
The most general criterion for site placement is suggested in the uneven distribution of earth circles in the Moreton Region. As noted, 87\% of sites occur in that portion of the region at or below $150 \mathrm{~m}$ above sea level. Furthermore, some 708 of sites occur in the Coastal Lowland and subcoastal Highland topographic subregions. Both of these factors correlate with more easterly location. This no doubt reflects the higher population density of this part of the region and indicates a preference for placing sites where they would be most accessible to the region's inhabitants.

At a more specific level, site location seems to have been influenced by the spatial relationships among sites. Here site morphology is relevant. Although ambiguous historical accounts and the partial destruction of some sites cloud the picture, it seems that sites exhibited a relatively narrow range of gross morphologies, with the overwhelming majority of sites originally consisting of either one or two rings and a pathway. Differences in such features as pathway direction and circle shape and orientation all appear to represent variations on a common theme.

Most of the sites in the region probably served equivalent functions, and this implies that they would not be placed in close proximity to one another. In fact, although analysis did not reveal any universal distance relationships among sites, there does appear to be a tendency toward regular distribution, at least to the extent that close spatial competition between sites was avoided. In addition, the majority of sites are placed equidistant from two or more neighbors, regardless of the specific distances involved. All of this indicates that site placement was often influenced by an awareness of distances to adjacent sites.

Placement in relation to other sites limits the number of possible site locations. The possibilities are limited even further, however, by the environmental requirements of site location. Earth circle sites have an identifiable association with sources of water, ridges, unstructured goils and geological boundaries. These factors are not necessarily independent. Creeks and rivers often adjoin ridges since the latter frequently form drainage divides between watercourses. Ridges may also be linked with ecotones, this because ridges can result from the variable weathering of different rock types at geological boundaries. Lastly, both ecotones and unstructured soils may be associated with watercourses; the former as areas of transition between riparian and other ecological communitieg and the latter as alluvial deposits in the vicinity of creeks and rivers.

Even though there is a degree of interdependence among them, it is possible to posit an order of priority for these environmental factors. If the control population reflects the proportional presence of these factors in the Moreton Region, then the degree of difference between actual and control populations would indicate the extent to which specific environmental features were sought out as particularly important to site location. In this case, sandy or loamy soil and ridges rank first, followed by perennial water within $1.0 \mathrm{~km}$ and a geological boundary within. $0.5 \mathrm{~km}$.

If this model has validity, then any remaining unknown sites have the greatest probability of being found at lower elevations, midway between already known sites, and on ridges providing readily dug soils in proximity to permanent water and geological boundaries. Since not all of the known site locations were examined in the field, further testing of the model 
shouid be undertaken in the context of an expanded field survey and data collection effort. The first priority of such a project should be the documentation, in terms of a consistent data-recording format, of: (1) the locations and morphologies of all existing sites in the Moreton and adjacent regions; (2) the locational and morphological details of any sites now destroyed or disappeared; (3) and all Aboriginal and non-Aboriginal knowledge of earth circle sites.

The collection of this information is especially pressing given the the gaps in the known distribution of sites and the vulnerability of earth circles to destruction. The areas for which there is inadequate information include the western and southwestern sections of the Moreton Region, the Woodridge-Beenleigh area, and the hinterland adjacent to south Stradbroke Island. A related concern is the dwindling number of people who have knowledge of unrecorded or no longer extant sites. Many of the people who provided valuable information during the course of this study are elderly residents of the region and there is great danger of their knowledge being lost.

An extended data base would assist investigation of several remaining problems concerning earth circles. A more complete picture of the distribution of these sites and the differences, often subtle, in morphologies may reveal spatial patterns not evident in existing data. It may also provide fuller understanding of the association between form and function, as well as help elucidate the connection between earth circle sites and other archaeological phenomena--habitation and workshop sites, carved trees and stone arrangements. Other problems requiring further investigation include the influence of local belief systems on site location, morphology and use, and the precise nature of the link between earth circles and features of Aboriginal social organization. Finally, although it is likely that existing sites are broadly contemporaneous, it is especially important that future research clarify the temporal relationships of these sites.

Periodic aggregation and dispersal appears to have been a general feature of Aboriginal social and ceremonial life in the region. And as with all sites, resource availability seems to have played a major role in ceremonial site location. In this case, however, large numbers of people congregated for ritual and other activities would have exhausted $10 \mathrm{cal}$ resources and precluded reuse of gathering places without an adequate period of resource recovery. As a consequence, frequent gatherings would have required use of a set of sites in rotation. It is significant in this regard that the Moreton Region contained so many earth circle sites, yet the foraging zones around them did not often overlap. The large number of sites in the region provided a large number of alternative locations for the holding of gatherings, while the lack of overlap in exploitation zones al lowed these areas of intensive foraging to lie fallow between episodes of use.

If this interpretation is correct, then the population of earth circle gites in the Moreton Region is best regarded as a site system. This perspective has both practical and theoretical implications. In practical terms, it emphasizes the importance of preserving all existing earth circles: each site not only has individual value, but also considerable importance as a component of the regional system. In terms of theoretical interests, few places. in the region were more than a day's walk from one of the sites in the system, and this has ramifications extending beyond the 
ecological and the economic. As a network of ritually significant places, earth circles reflect the imposition of ideologically derived order on the Moreton landscape; as a set of venues for large gatherings, initiation and dispute settlement, the earth circle system provided a tangible framework for the structuring of complex forms of social interaction; and as deliberate constructions, rather than the incidental consequence of other activities, earth circles constituted principal elements of the region's Aboriginal built environment.

This last point has special significance. The ubiquity of earth circles in the region denotes Aboriginal domestication of the Moreton environment--in effect, by establishing these sites the Aboriginal people of the region signaled their appropriation of it by transforming its natural landscape into cultural landscape.

\section{ACKNOWLEDGMENTS}

This article represents a re-appraisal and extension of earlier work (see Heather 1983). A number of people have contributed to various phases of the project: John steele (Department of Physics, University of Queensland) kindly provided access to unpublished site descriptions; Lloyd Sandilands (Department of Civil Engineering, University of Queensland) and Dennis Baker (Queensland Department of Primary Industries) assisted with soil tests; Eric Savage and Alan Victor (Department of Geography, Univergity of Queensland) loaned maps and equipment; Glenda Acland (University of Queensland Archives) located important documents and files; Michael Quinnel 1 and Richard Robins (queensland Museum) provided information from museum records; and Mike Rowland (Archaeology Branch, Department of Community Services) and J. Hall (Department of Anthropology and Sociology, University of Queensland) assisted with information, comments and suggestions. We are indebted to them all.

\section{REFERENCES CITED}

Altman, J.C. 1983 Eastern Gunwinggu figh trapping at Gunbatgarri. The Beagle 1:59-71.

Altman, J. 1987 Hunter-Gatherers Today. Canberra: Australian Institute of Aboriginal studies.

Barker, G. 1976 The ritual estate and Aboriginal polity. Mankind 10:225239.

Basile, R.M. 1973 A Geography of Soils. Dubuque, Iowa: william C. Brown.

Bern, J. 1979 Politics in the conduct of a secret male ceremony. Journal of Anthropological Research 35:47-60.

Berndt, R.M. and C.H. Berndt 1977 The world of the First Australians. Sydney: Ure Smith.

Billings, W.D. 1970 Plants, Man and the Bcosystem. Belmont, New York: Wadsworth Publishing. 
Binford, L.R. 1980 willow smoke and dogs' tails: hunter-gather settlement systems and archaeological site formation. American Antiquity $45: 4-20$.

Bureau of Meteorology 1977 climate of Brisbane. Canberra: Australian Government Publishing Service.

Butlin, N. 1983 Our Original Aggression. Sydney: Allen and Unwin.

Clark, P.J. and F.C. Evans 1954 Distance to nearest neighbor as a measure of spatial relationships in populations. Ecology 35:445-453.

Co-ordinator General's Department 1972 Moreton Region: Natural Environment. Brisbane: Government Printer.

Davis, J. 1861 Evidence presented. Report from the select Committee on the Native Police Force and the Condition of Aborigines General1y: together with the proceedings of the committee and minutes of evidence. Queensland Votes and Proceedings. Brisbane: Fairfax and Bel bridge.

Department of Mines 1980 Moreton Geology Map. Brisbane: Government Printer.

Donovan, D. 1895 The 'Bora' at Gatton. The Queenslander, 30 November, p. 1034 .

Draper, N. 1980 Food resources of the Moreton Bay Aborigines. Occasional Papers in Anthropology 10:124-147.

Flood, J. 1980 The Moth Hunters. Canberra: Australian Institute of Aborignal studies.

Gresty, J.A. 1947 The Numinbah Valley: its geography, history and Aboriginal associations. Queensland Geographical Journal 51:57-72.

Ha11, H.J. 1982 sitting on the crop of the bay: an historical and archaeological sketch of Aboriginal settlement and subsistence in Moreton Bay. In S. Bowdler (ed.), The Coastal Archaeology of Eastern Australia, pp. 79-85. Canberra: Department of Prehistory, Research School of Pacific studies, Australian National University.

Ha 1 1, T. 1907 A Short History of the Downs Blacks Known as "The Blucher Tribe". Warwick.

Hamilton, A. 1980 Dual social systems: technology, labour and women's secret rites in the eastern Western Desert of Australia. Oceania 51:4-19.

Hammond, R. and P. MCCullogh 1974 Quantitative Techniques in Geography. London: Oxford University Press.

Hardcastle, T.W: 1947 A vocabulary of the Yuggarabul language. Queens 1 and Geographical Journal 51:21-28. 
Hodder, I. 1977 Some directions in the spatial analysis of archaeological data at the regional scale (macro). In D.L. Clarke (ed.), Spatial Archaeology, pp. 223-351. London: Academic Press.

Hodder, I. and C. Orton 1976 Spatial Analysis in Archaeology. Cambridge: Cambridge University Press.

Howitt, A.W. 1904 The Native Tribes of South-east Queensland. London: Macmilian.

Hsu, S. and C.E. Tiedemann 1968 A rational method of delimiting study areas for unevenly distributed point phenomena. Professional Geographer 20:376-381.

Jochim, M.A. 1976 Hunter-Gatherer Subsistence and settlement: A Predictive Kode1. New York: Academic Press.

Langevad, G. 1979 The Simpson letter-book. Cultural and Historical Records of Queensland No. 1. Brisbane: University of Queengland Anthropology Museum.

Liliey, I. 1982 A finger on the pulse: analysis of site location patterns in subcoastal southeast Queensland. Unpublished M.A. Thesis, University of Queensland.

Lilley, I. 1984 Late holocene subsistence and settlement in subcoastal Southeast Queensland. Queensland Archaeological Research 1:8-32.

Lourandos, H. 1980 Change or stability?: hydraulics, hunter-gatherers and population in temperate Australia. World Archaeology 11:245-264.

Lourandos, H. 1983 Intensification: a Late Pleistocene-Holocene archaeological sequence from southwestern victoria. Archaeology in oceania 18:81-94.

Lourandos, H. 1985 Intensification and Australian prehistory. In D.T. Price and J.A. Brown (eds.), Prehistoric Hunter-Gatherers: The Emergence of Cultural Complexity, pp. 385-423. New York: Academic Press.

McBryde, I. $1974 a$ Aboriginal Prehistory in New England. Sydney: Sydney University Press.

McBryde, I. $1974 \mathrm{~b}$ Mathews, Robert Hamilton (1841-1918). In Australian Dictionary of Biography 1851-1890, Vol. 5, p. 225. Melbourne: Melbourne University Press.

MCBryde, I. 1979 Ethnohistory in an Australian context: independent discipline or convenient data quarry? Aboriginal History 3:128151 .

Marks, E. 1970 A list of Bora grounds in South-east Queensland: compiled for the directors of the Bornong Project. Typescript held at the Archaeology. Branch, Queensland Department of Community Services, Brisbane. 
Mathew, J. 1887 Mary River and the Bunya-Bunya country. In E.M. Curr (ed.), The Australian Race, pp. 152-213. Melbourne: Government Printer.

Mathew, J. 1910 Two Representative Tribes of Queensland. London: T. Fisher Unwin.

Mathews, R.H. 1894 Aborignal Bora held at Gundabloui in 1894. Proceedings and Journal of the Royal Society of New South Wales 28:98-129.

Mathews, R.H. 1900 The Toara ceremony of the Dippil Tribes of Queensland. American Anthropologist 2:139-144.

Mathews, R.H. 1910 Initiation ceremonies of some queensland tribes. Queensland Geographical Journal 25:103-118.

Meggitt, M.J. 1962 Desert People. Sydney: Angus and Robertson.

Meston, A. 1895 Geographic History of Queensland. Brisbane: Government Printer.

Myers, F. 1980a The cultural basis of Pintubi politics. Mankind 12:197213.

Myers, F. 1980b A broken code: a Pintubi political theory and contemporary social life. Mankind 12:311-326.

Mulvaney, DiJ. 1976 The chain of connection: the material evidence. In N. peterson (ed.), Tribes and Boundaries in Australia, pp. $72-94$. Canberra: Australian National University Press.

Norton, A.P. and J.G. Inglis 1966 Norton's Star Atlas. Edinburgh: Gall and Inglis.

O'Connell, J.F. 1979 Room to move: contemporary Alyawara settlement patterns and their implications for Aboriginal housing policy. In M. Heppel (ed.), A Black Reality, pp. 97-120. Canberra: Australian Institute of Aboriginal studies.

Peterson, N. 1973 Campsite location amongst Australian hunter-gatherers: archaeological and ethnographic evidence for a key determinant. frchaeology and Physical Anthropology in Oceania 8:173-193.

Petrie, c.C. 1904 Tom Petrie's Reminiscences of Barly Queensland. Brisbane: Watson and Ferguson.

Queensland Electricity Generating Board 1980 Bora ring preserved. QEGB Newgline $14: 8$.

Riches, D. 1982 Northern Nomadic Hunter-Gatherers: A Humanistic Approach. London: Academic Press.

Robingon, F.W. 1952 On the location and preservation of Aboriginal relics and survivals in Queensland, especially of ceremonial Bora rings. Correspondence in subject file UQA S130, "old" series, c.19111966,1965-1966, Anthropology collection-preservation of Aboriginal ceremonial grounds and other archaeological sites, University of Queensland Archives. 
Satterthwait, L. 1987 Socioeconomic implications of Australian Aboriginal net hunting. Man 22(n.s.):613-636.

Shirley, J. 1911 A Bora ring in the Albert Valley. Proceedings of the Royal Society of Queensland 23:103-105.

Steele, J.G. 1972 The Explorers of the Moreton Bay District 1770-1830. Brisbane: University of Queensland Press.

Steele, J.G. 1975 Brisbane Town in Convict Days, 1824-1842. Brisbane: University of Queensland Press.

Steele, J.G. 1984 Aboriginal Pathways in Southeast Queensland and the Richmond River. Brisbane: University of Queensland Press.

Strahler, A.N. and A.H. Strahler 1973 Environmental Geoscience: Interaction Between Natural Systems and Man. Santa Barbara, California: Hamilton Publishing.

Sullivan, H. 1977 Aboriginal gatherings in Southeast Queensland. Unpublished B.A. (Hons) Thesis, Australian National University.

Taylor, J.C. 1967 Race relations in South-east Queensland. Unpublished B.A. (Hons) Thesis, University of queensland.

Thomson, D.F. 1949 Economic structure and the Ceremonial Bxchange Cycle in Arnhem Iand. Melbourne: Macmillan.

Van Ripper, J.E. 1971 Man's Physical World. New York: McGraw-Hill.

Walter, H. 1973 Vegetation of the Earth in Relation to climate and the Eco-Physiological Conditions. London: English Universities Press .

Walters, G.A. 1974 Araucaria. In C. Schopmeger (ed.), Seeds of Woody Plants in the United States. Agricultural Handbook No. 450. Washington, D.C.: United States Department of Agriculture.

Welsby, T. 1967 Memories of Amity (1922). In A. Thomson (ed.), The Collected Horks of Thomas Helsby, Vol. 2, pp. 79-201. Brisbane: Jacaranda Press.

Whalley, P. 1987 An introduction to Aboriginal social history, Moreton Bay, South-east Queensland, 1799-1880. Unpublished B.A. (Hons) Thesis, University of Queensland.

Winterbotham, L.P. 1983 The Gaiarbau story [G. Langevad, ed.]. Queensland Bthnohistory Transcripts $1: 21-111$. 